\title{
Focal prices and price cycles in an alternating price duopoly experiment
}

Citation for published version (APA):

Leufkens, K., \& Peeters, R. J. A. P. (2008). Focal prices and price cycles in an alternating price duopoly experiment. METEOR, Maastricht University School of Business and Economics. METEOR Research Memorandum No. 021 https://doi.org/10.26481/umamet.2008021

Document status and date:

Published: 01/01/2008

DOI:

10.26481/umamet.2008021

Document Version:

Publisher's PDF, also known as Version of record

\section{Please check the document version of this publication:}

- A submitted manuscript is the version of the article upon submission and before peer-review. There can be important differences between the submitted version and the official published version of record.

People interested in the research are advised to contact the author for the final version of the publication, or visit the DOI to the publisher's website.

- The final author version and the galley proof are versions of the publication after peer review.

- The final published version features the final layout of the paper including the volume, issue and page numbers.

Link to publication

\footnotetext{
General rights rights.

- You may freely distribute the URL identifying the publication in the public portal. please follow below link for the End User Agreement:

www.umlib.nl/taverne-license

Take down policy

If you believe that this document breaches copyright please contact us at:

repository@maastrichtuniversity.nl

providing details and we will investigate your claim.
}

Copyright and moral rights for the publications made accessible in the public portal are retained by the authors and/or other copyright owners and it is a condition of accessing publications that users recognise and abide by the legal requirements associated with these

- Users may download and print one copy of any publication from the public portal for the purpose of private study or research.

- You may not further distribute the material or use it for any profit-making activity or commercial gain

If the publication is distributed under the terms of Article $25 \mathrm{fa}$ of the Dutch Copyright Act, indicated by the "Taverne" license above, 
Kasper Leufkens, Ronald Peeters

Focal prices and price cycles in an alternating price duopoly experiment

$\mathrm{RM} / 08 / 021$

JEL code: C91, D43

\section{METE@R}

Maastricht research school of Economics of TEchnology and ORganizations

Universiteit Maastricht

Faculty of Economics and Business Administration P.O. Box 616

NL - 6200 MD Maastricht

phone : ++31433883830

fax : ++31433884873 


\title{
Focal prices and price cycles in an alternating price duopoly experiment*
}

\author{
Kasper Leufkens ${ }^{\ddagger} \quad$ Ronald Peeters ${ }^{\ddagger \S}$
}

July 29, 2008

\begin{abstract}
In the infinite horizon alternating price setting duopoly of Maskin and Tirole (1988), a focal price equilibrium and an equilibrium consisting of Edgeworth cycles coexist. In this study we investigate which of these two equilibria is more likely to emerge by means of a laboratory experiment. In 20 out of 27 observations the focal price equilibrium emerges, while price cycles are observed in only one observation. Furthermore, we study the duopoly in case of a long but finite horizon. Although the corresponding unique subgame-perfect equilibrium consists of Edgeworth cycles, experimentally we still observe a focal price in the majority of the observations. Nevertheless, price cycles are observed far more often than for the infinite horizon setting.
\end{abstract}

JEL Classification Codes: C91, D43.

Keywords: Alternating move, price setting, experiment, price cycles.

\section{Introduction}

In oligopolistic markets, prices often fluctuate even though demand and supply conditions are stable. Frequently, the rocket-feather pricing pattern is observed, where a series of small price decrements is followed by a sudden substantial increment, after which prices start declining again, possibly after a period of stable prices. Empirical studies have found such a pattern for local gasoline markets in the United States (Castanias and Johnson, 1993, and Doyle et al., 2007), Canada (Eckert, 2003, and Noel, 2007), and Australia (Wang, 2005). Similarly, a price pattern consisting of periods of stability followed by gradual undercutting of competitors' prices has been observed for the airline industry (Ross, 1997, and Busse, 2002).

The traditional price setting model for an oligopolistic market was introduced by Bertrand (1883). For homogeneous objects this model predicts that, in equilibrium, prices equal marginal cost. Consequently, prices are stable and firms do not make any profit. Edgeworth (1925) showed that, in contrast to the static price equilibrium of Bertrand, prices do cycle

\footnotetext{
${ }^{*}$ We thank conference participants in Alicante (IMEBE 2008) for helpful comments and suggestions.

${ }^{\ddagger}$ Department of Economics, Maastricht University, P.O. Box 616, 6200 MD Maastricht, The Netherlands.

${ }^{\S}$ Corresponding author, email: R.Peeters@algec.unimaas.nl.
} 
when firms face capacity constraints and set prices repeatedly. In this so-called Edgeworth cycle, firms successively undercut each others' prices until the 'war' becomes too expensive and one firm increases its price. Next, the other firms respond with a match or a slight undercut, after which the process of undercutting resumes. This result, however, is induced by the competitors' mutual irrational expectation that opponents maintain their prices from the previous period.

In opposition, Chamberlain (1933) claims that a small number of firms will not start undercutting but rather charge the monopoly price. The firms will realize their interdependence and that competitors will retaliate a price cut by also cutting their prices. Therefore, the result of a price cut will be a decrease in its own profits. Hall and Hitch (1939) and Sweezy (1939) formalize this conjecture by showing that a focal price equilibrium can be sustained for a kinked demand curve.

Maskin and Tirole (1988) show that the equilibria envisioned by Edgeworth and Chamberlain can coexist for an infinite time horizon. They show that when firms face short-run price commitments, which is modeled via alternating price setting, both a focal price equilibrium and an equilibrium consisting of Edgeworth cycles emerge as a Markov perfect equilibrium. In the focal price equilibrium, prices are stable at the monopoly price. In the Edgeworth cycles equilibrium, prices decline gradually to marginal cost after which one of the firms raises the price again and the undercutting resumes.

A different line of theoretical explanations for periods of stable prices and periods of successive undercutting concerns tacit collusion. Price wars can erupt due to uncertainty related to the market conditions. Green and Porter (1984) consider a model in which firms face uncertainty about current demand such that price cutting detection is hindered. Optimal punishment is not to resort to the Bertrand equilibrium forever but involves a finite number of periods after which a collusive price is again adopted. Furthermore, Rotemberg and Saloner (1986) show that collusive prices move countercyclically in case market demand is stochastic.

Evidence of price cycles in experiments is rather limited. Cason et al. (2005) find that for some variations of the Edgeworth hypothesis, the data of repetitive posted price offers by six sellers displays a cycle. Furthermore, Kruse et al. (1994) observe price cycles when capacity is restricted and there are four players. Guillén (2004) finds price cycles for an experiment involving simultaneous price and quantity setting. However, in the same setting, price cycles are not observed in case of two or three sellers (Brandts and Guillén, 2003).

In this paper, by means of a laboratory experiment, we investigate the potential to observe price cycles in the alternating price setting of Maskin and Tirole (1988) with two players. We consider the infinite and the finite time horizon versions of this model. For the infinite time horizon there exists a Markov perfect equilibrium with stable prices besides a Markov perfect equilibrium that displays price cycles. For the finite time horizon, the subgame-perfect equilibrium induces a cyclical pricing pattern. Strikingly, the backwards induction strategies do not converge to stationary behavior when the horizon lengthens. In our experiment, we 
find that in an infinite horizon setting, the focal price equilibrium emerges in 20 out of 27 observations and price cycles in only one observation. For the finite horizon setting, we also observe the focal price outcome in the majority of the observations, even though it is not predicted by subgame-perfect Nash equilibrium. However, we observe clear price cycles in three and price wars in two out of the fifteen observations.

The remainder of this paper is organized as follows. In Section 2, we present the basic model and the Markov perfect equilibria for the infinite time horizon of the model and the subgame-perfect Nash equilibrium in case the time horizon is finite. In Section 3, the experimental design and procedures are described. The analysis of the data is presented in Section 4. The paper ends with some concluding remarks in Section 5.

\section{Setting}

The setting that we consider is precisely the illustrating example of the exogenous-timing duopoly model of Maskin and Tirole (1988). The two firms compete in a homogenous product market with prices being the strategic variable. Firms interact dynamically in discrete time and can adapt their prices alternately. So, in the periods in which a firm cannot adapt its price, the price remains equal to the price set in the previous period. Consequently, firms set prices for two periods. This alternating move structure captures the idea of short-run price commitments. Without loss of generality, we assume that firm A can adapt its price in odd periods and firm B in even periods.

The prices that firms can charge are the seven integers between (and including) 0 and 6. Given the firms prices at a certain period, $p^{A}$ and $p^{B}$, the market price for that period equals $p^{*}=\min \left\{p^{A} ; p^{B}\right\}$. The market demand for that period is given by $D\left(p^{*}\right)=6-p^{*}$. We assume that the firms do not incur any costs for production. Consequently, the market profit equals $\Pi\left(p^{*}\right)=p^{*} \cdot D\left(p^{*}\right)$. Table 1 summarizes the possible market prices and the resulting market demand and market profit. The products are homogeneous and therefore only the

\begin{tabular}{llllllll}
\hline Market price & 0 & 1 & 2 & 3 & 4 & 5 & 6 \\
Market demand & 6 & 5 & 4 & 3 & 2 & 1 & 0 \\
\hline Market profit & 0 & 5 & 8 & 9 & 8 & 5 & 0 \\
\hline
\end{tabular}

Table 1: The output and profit for the seller with the lowest price.

firm with the lowest price sells output. This means that if a firm has the unique lowest price, this firm receives the full market profit. In case both firms charge the same price, the market demand and the market profit are split equally among them.

Next, we consider this setting with an infinite and a finite time horizon. 


\subsection{Infinite horizon}

Suppose that the time horizon is infinite and future profits are discounted by a factor $\delta$. It is assumed that this discount factor is sufficiently close to, and strictly smaller than one. Firms maximize the present value of the infinite stream of profits. Maskin and Tirole (1988) solve this setting for strategies that only depend on the payoff relevant state, which is in this case the price set by the other firm in the previous period. Consequently, strategies are dynamic reaction functions that give a response price for each price set by the other firm. There are two Markov perfect equilibria that coexist: a focal price equilibrium and an equilibrium that consists of Edgeworth cycles. ${ }^{1}$

In the focal price equilibrium, the firms always set prices equal to 3 which is then also the market price. Hence, the market demand and profit is split equally and each firm makes a profit of 4.5 in all periods. The symmetric equilibrium strategy and the prices set along the equilibrium path are shown in Figure 1.

\begin{tabular}{|c|c|}
\hline Price & Response price \\
\hline 6 & 3 \\
\hline 5 & 3 \\
\hline 4 & 3 \\
\hline 3 & 3 \\
\hline 2 & 1 \\
\hline \multirow[t]{2}{*}{1} & with probability $\beta(\delta)$ \\
\hline & with probability $1-\beta(\delta)$ \\
\hline \multirow[t]{2}{*}{0} & 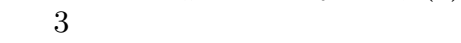 \\
\hline & $\beta(\delta) \equiv(5+\delta) /\left(5 \delta+9 \delta^{2}\right)$ \\
\hline
\end{tabular}

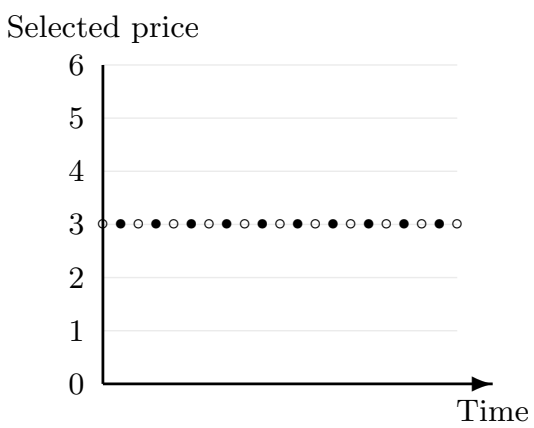

Figure 1: Focal price equilibrium. Left panel: symmetric MPE strategy. Right panel: selected price by the respective firm in the respective period $(\bullet=$ firm $1 ; \circ=$ firm 2$)$.

As soon as one of the two firms sets a price of 3 , prices remain there ever after. From any price above 3 , the equilibrium response brings the price immediately down to 3 . From prices below 3, prices are not instantly changed to 3, but do end up there with probability one. Bringing the price up from 1 to 3 is costly and therefore each firm prefers the other firm to do so. The probability $\beta(\delta)$ is determined in such a way that the firm is indifferent between raising and not raising the price.

The other Markov perfect equilibrium induces a cyclical pricing pattern on the equilibrium path. The symmetric equilibrium strategy and the prices set along the equilibrium path are shown in Figure 2. The firms undercut each other's price successively until the price equals zero and neither firm makes a positive profit. At that price, each firm has an incentive to raise its price. Furthermore, each firm prefers the other firm to raise its price first, so that it can start undercutting in the subsequent period. The probability $\alpha(\delta)$ is determined in such a way that the firm is indifferent between raising and not raising the price. After one firm

\footnotetext{
${ }^{1}$ For proofs see Maskin and Tirole (1988). They refer to the focal price equilibrium as a kinked demand curve. For our experimental context it is more intuitive to interpret it as the focal price equilibrium.
} 
has raised the price, the undercutting starts again. The price cycles consist of two phases: an undercutting phase and a coordination phase concerning which firm is going to raise the price when the price equals zero. In equilibrium, all prices except 6 are observed.

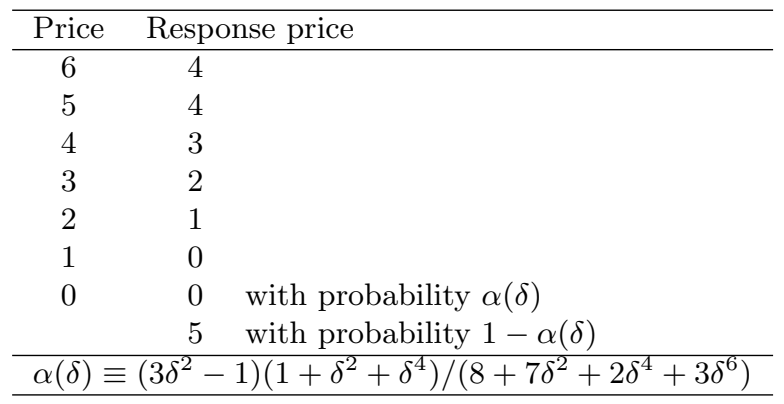

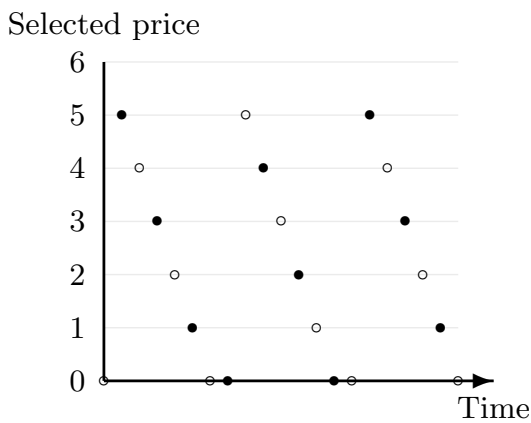

Figure 2: Edgeworth cycle equilibrium. Left panel: symmetric MPE strategy. Right panel: selected price by the respective firm in the respective period $(\bullet=$ firm $1 ; \circ=$ firm 2$)$.

\subsection{Finite horizon}

In this subsection, we consider a similar setting but then with a finite time horizon without discounting. For a fixed horizon, the resulting game can be solved by application of the backwards induction procedure. Obviously, the best response in the last period is to undercut the opponent if possible. Considering the profit structure of the game, this still does not imply that for long horizons prices constant at 1 are observed. It appears that when the horizon lengthens, the backwards induction outcome converges to a pricing pattern that contains recurrent cycles (as long as the final stage is not too near). The best responses within a cycle not only depend on the current price of the opponent, but also on the number of periods that have elapsed since the start of the cycle. The non-stationary pricing behavior within a cycle is illustrated in Figure 3.
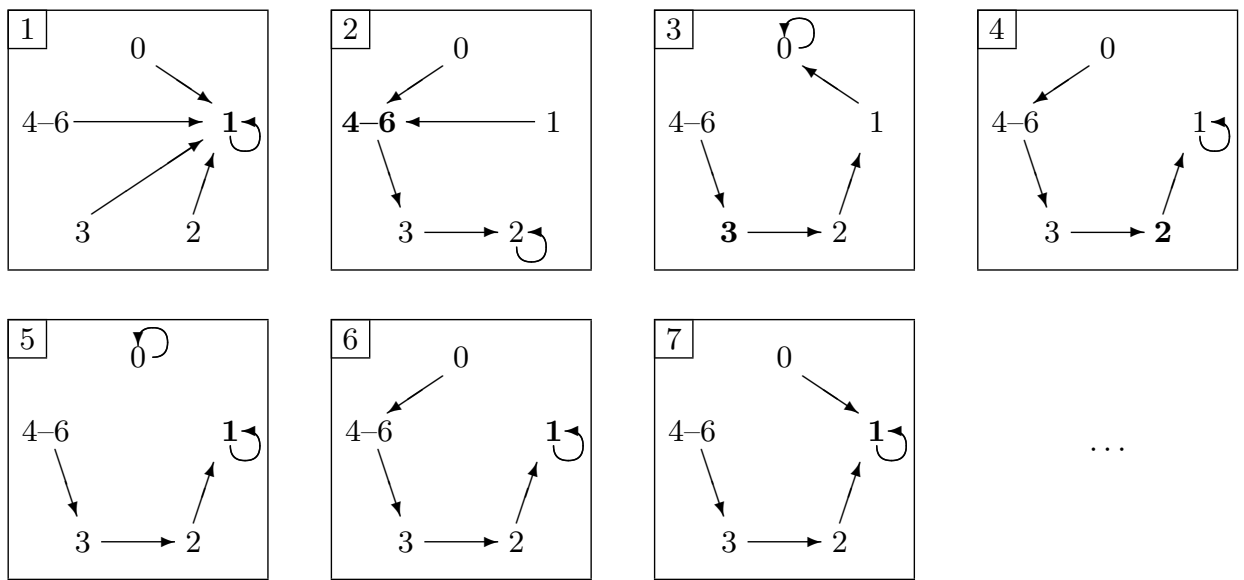

Figure 3: Best responses for long finite horizons. 
The seven boxes represent periods 1 to 7 of a price cycle. In each box, an arrow shows the best response for each current price of the opponent. The price that will be set along the equilibrium path is shown in boldface in each box. In box 1, the best response is to set the price equal to 1, regardless of the opponent's current price. Note that the actual period in time at which this behavior is observed is not specified, we take it as the first of the cycle since the resulting price is 1 in any case. Next, in box 2, the price of 1 is responded with one of the prices 4, 5 and 6 . By overshooting the current market price, the opponent foregoes any immediate profit in exchange for future profits. In box 3 , no matter which of the three prices were chosen in box 2 , the response is to undercut this price by setting the price equal to 3 . Thereby the maximum immediate profit of 9 is gained. Consequently, in the previous box the opponent is indeed indifferent between setting a price of 4,5 , or 6 . Next, in box 4 , the opponent undercuts this price by setting its price equal to 2 , and this price is again undercut by a price of 1 in box 5 . Then, the price remains at 1 in box 6,7 and 1 in order to be brought up in box 2 and subsequently to start the gradual undercutting.

Although the figure only presents seven boxes, the cycle has a length of fourteen periods. Namely, if it is the one firm that played according to the action displayed in box 1, after having reached box 7 , it is the other firm that continues with the action that is depicted in box 1. Nevertheless, the dynamics of the prices being selected over periods follows a cyclical pattern with cycle length of seven. A graphical illustration of the cycle is given in Figure 4 . The figure does not contain prices observed in initial periods or periods close to the horizon.

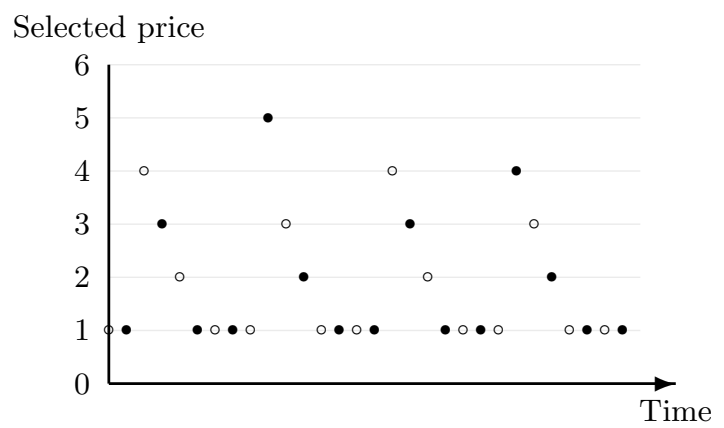

Figure 4: Cyclical pattern of selected prices $(\bullet=$ firm $1 ; \circ=$ firm 2$)$.

\section{$3 \quad$ Experimental design and procedures}

In our experiment, we study subjects' behavior in the alternating price setting model for the infinite and the finite (but lengthy) time horizon. Our experimental design, hence, consists of two treatments that are equal apart from the way the number of periods is determined. In the first treatment we implemented a random continuation rule, whereas in the other treatment we have a fixed number of periods. 
In the treatment with random ending, each period there was a two percent probability that the experiment ended after that period. Of course, it requires a sufficiently long horizon in order to be able to find mature behavior. In order to increase chances on having a session with a sufficiently long horizon, we scheduled two sessions for this treatment. Within a session, all subjects faced the same horizon. In the end, the experiment consisted of 67 periods in the first session, and of 40 periods in the second session. ${ }^{2}$ In the treatment with fixed ending, the experiment ended after 80 periods. In both treatments, subjects were perfectly informed about the determination of the number of periods. The treatments are summarized in Table 2 .

\begin{tabular}{lccc}
\hline & \multicolumn{2}{c}{ Random ending } & Fixed ending \\
\cline { 2 - 3 } & Session 1 & Session 2 & \\
\hline Periods & 67 & 40 & 80 \\
Observations & 15 & 12 & 15 \\
\hline
\end{tabular}

Table 2: The experimental treatments.

At the beginning of the session, subjects were randomly matched in pairs and it was common knowledge that the matching did not change throughout the experiment. Subjects, however, never learned the identity of the subject they were matched with. Before the first period started, for each matched pair of subjects, it had to be decided who of the two subjects can adapt the price in the first (and hence each odd) period and what price was responded to in this first period. Therefore, the experiment started with a pre-stage phase in which both subjects simultaneously had to set an initial price. Next, it was randomly decided which of the two subjects could adapt the price in the first period. In the first period, this subject responded to the other's price set in the pre-stage phase. ${ }^{3}$

Every period, the subjects that were able to adapt their prices could observe the current period price of their opponent. Prices were selected by marking one of the seven possible prices. At the end of each period, subjects received an overview of the results of that period, which consisted of both prices, own profit, and own total profit so far. In periods where subjects could not adapt their price, they only observed the result screen of that period.

The experiment was conducted in the behavioral and experimental laboratory (BeeLab) of the Faculty of Economics and Business Administration at Maastricht University in November 2007. The laboratory has a capacity of 32 students and we allowed precisely 32 students to register for each of the three sessions. The experiment was announced via email and subjects could register online using their matriculation number, which ensured that students could participate only once. When students arrived at the laboratory, they had to draw a card from a deck that determined at which computer terminal they were placed. In case an odd number of students showed up for a session, we included a blank card in the deck. Students that drew the blank card could not participate and were paid $€$ 3.- as compensation. In

\footnotetext{
${ }^{2}$ See Selten et al. (1997) and Dal Bó (2005) for discussions on approximating infinitely repeated games in experiments.

${ }^{3}$ The pre-stage price of the subject that could adapt its price in the first period was never revealed.
} 
total, 84 undergraduate students participated in the experiment. Students not showing up or cancelling on short notice led to the dispersion in the number of independent observations.

All interactions took place via computers that were connected to a network and the computer terminals were placed in such a way that subjects could neither see the screens of others nor make eye contact with them. The experiment was programmed and conducted with the software z-Tree (Fischbacher, 2007). Before the start of a session, subjects read the instructions and were allowed to privately ask questions that were then privately answered. After reading the instructions, subjects had to answer control questions, which tested their understanding of the instructions. ${ }^{4}$ One of the experimenters checked the answers, and the experiment only started after all subjects answered each question correctly. During the experiment, subjects earned ECU that were converted into Euros at a known exchange rate at the end of the experiment. We used the same exchange rates in both treatments and $20 \mathrm{ECU}$ was exchanged for 1 Euro. The average payoff was $€ 17.78$ including a show-up fee of $€ 5$.-. Sessions lasted, depending on the treatment, between 45 and 70 minutes. Payment took place privately, and subjects had to leave the laboratory immediately after payment.

\section{Results}

In this section we analyze the experimental price setting behavior. For both treatments, it is found that the major share of the groups coordinated on a price of 3 (the focal point equilibrium for the infinite time horizon). Groups where the price settled down at 2 form a small minority. Finally, there is a large minority of groups where prices did not converge and displayed some kind of cyclical behavior. For the groups in the latter category, we pursue a deeper investigation in the underlying pricing dynamics. In doing so, we neglect premature decision making in both treatments and endgame effects in the fixed ending treatment by neglecting the prices set in the first fourteen periods and the last six periods. ${ }^{5}$

\subsection{Random ending}

For this treatment we have in total 27 independent observations spread over two sessions. In the first session, 15 pairs of subjects played for 67 periods. The remaining 12 pairs of subjects played in the second session which consisted of 40 periods. If subjects' behavior would be consistent with common belief in sequential rationality and Markovian behavior, we should observe one of the two equilibria of Subsection 2.1. That is, prices are constantly 3, or would follow the rocket-feather pattern of prices gradually falling to 0 , where at some point the price rockets to 5 . All decisions made throughout these experimental sessions are presented in Appendix A.

\footnotetext{
${ }^{4}$ See Section $\mathrm{C}$ for the instructions and control questions.

${ }^{5}$ Changing the categories by a couple of periods does not lead to different conclusions.
} 
Apart from Groups R1.6, R2.5, R2.6, R2.7 and R2.11, subjects managed to coordinate on a common price. Groups R1.15 and R2.1 settled down at a price of 2. The remaining 20 groups settled down at a price of 3 . So, a majority of the groups play according to the focal price equilibrium. Four of these 20 groups - namely: R1.9, R1.10, R1.13, and R2.9-need more than 15 periods for getting to this equilibrium. The other 16 groups manage to get to this equilibrium rather quickly. Next, we study the dynamics of pricing behavior for those five groups that did not settle down at a single common price in more detail.

One property of a price cycle is that a range of prices is observed. In addition, subjects should gradually undercut each other's price until the prices reach a certain bottom level. Undercutting behavior above the bottom price can be identified by a rather high conditional probability that $p_{t+1}=p_{t}-1$. When prices have reached the bottom, they are likely to stay there for some periods due to the coordination problem for bringing prices up. Consequently, having the mode at the bottom of the price range may indicate some form of cycling behavior. ${ }^{6}$ For the relevant five groups, Table 3 displays the conditional switching probabilities for the observations after period 15. For Group R1.6 these probabilities are based on 52 decisions, and for Groups R2.5, R2.6, R2.7 and R2.11 on 25 decisions each. Each entry in the table shows the probability that a current price of $p_{t}$ is followed by a price of $p_{t+1}$ in the subsequent period. The last row shows the number of observations on which the probabilities are based for each of the possible current prices.

All five observations share the common property that once a price larger or equal to 4 is set, it will immediately be undercut. In Group R2.5 a price of 3 is as likely being undercut as being matched. In the other four out of five observations, also a price of 3 is immediately undercut. Apart from Group R2.7, prices of 2 and 1 are matched with high probability. These groups therefore do not display active cyclical behavior as the price often tends to stagnate at 1 or 2 . In these observations prices larger or equal to 3 are not frequently observed. In Group R2.7, a price of 2 is undercut with certainty. One period later, when the price has reached the bottom of the price cycle at price 1 , in this group, the price is matched with probability 0.33 and brought up with probability 0.67 in order to continue the process of gradual undercutting.

The only observation, out of the 27 in total, that comprises the conditions of a price cycle is Group R2.7. All prices higher than 1 are followed by a price that is one below it in the subsequent period. After the price has dropped to 1 , it either remains there or it is (substantially) increased. Even though prices do clearly cycle, the behavior does not completely match the price cycle equilibrium of Maskin and Tirole (1988). Namely, in this

\footnotetext{
${ }^{6}$ In empirical studies a negative median price change is sometimes taken as an indication of cycling prices (see Lewis (2006) and Doyle et al. (2007)). In these studies prices are set on a much finer grid and therefore hardly ever the same in subsequent periods. For the present experiment this is not a suitable classification measure since the coordination stage at the bottom of the cycle can take quite long and hence the median price change will be zero even if prices do cycle. Actually, the median price change equals zero in the backwards induction equilibrium of the finite horizon setting which clearly consists of price cycles.
} 


\begin{tabular}{clllllll}
\hline \multicolumn{7}{c}{ Group R1.6 } \\
\hline & \multicolumn{7}{c}{$p_{t}$} \\
\cline { 2 - 8 }$p_{t+1}$ & 6 & 5 & 4 & 3 & 2 & 1 & 0 \\
\hline 6 & & & 0 & 0 & 0 & 0 & 0 \\
5 & & & 0 & 0 & 0 & 0 & 0 \\
4 & & & 0 & 0 & 0 & 0.07 & 0 \\
3 & & & 1 & 0 & 0.04 & 0 & 0.33 \\
2 & & & 0 & 1 & 0.81 & 0 & 0.33 \\
1 & & & 0 & 0 & 0.15 & 0.60 & 0.17 \\
0 & & & 0 & 0 & 0 & 0.33 & 0.17 \\
\hline$\#$ & 0 & 0 & 1 & 4 & 26 & 15 & 6 \\
\hline
\end{tabular}

\begin{tabular}{cccllllll}
\hline \multicolumn{1}{c}{ Group R2.5 } \\
\hline & \multicolumn{7}{c}{$p_{t}$} \\
$n_{t+1}$ & 6 & 5 & 4 & 3 & 2 & 1 & 0 \\
\hline 6 & & & 0 & 0 & 0 & 0 & \\
5 & & & 0 & 0 & 0 & 0 & \\
4 & & & 0 & 0.14 & 0 & 0 & \\
3 & & & 1 & 0.43 & 0.17 & 0.20 & \\
2 & & & 0 & 0.43 & 0.67 & 0.20 & \\
1 & & & 0 & 0 & 0.17 & 0.60 & \\
0 & & & 0 & 0 & 0 & 0 & \\
\hline$\#$ & 0 & 0 & 1 & 7 & 12 & 5 & 0 \\
\hline
\end{tabular}

\begin{tabular}{clllllll}
\hline \multicolumn{1}{c}{ Group R2.6 } \\
\hline & \multicolumn{7}{c}{$p_{t}$} \\
\cline { 2 - 8 }$p_{t+1}$ & 6 & 5 & 4 & 3 & 2 & 1 & 0 \\
\hline 6 & & & 0 & 0 & 0 & 0 & 0 \\
5 & & & 0 & 0 & 0 & 0 & 0 \\
4 & & & 0 & 0 & 0 & 0.09 & 0 \\
3 & & & 1 & 0 & 0.11 & 0.09 & 0 \\
2 & & & 0 & 1 & 0.78 & 0 & 0 \\
1 & & & 0 & 0 & 0.11 & 0.82 & 1 \\
0 & & & 0 & 0 & 0 & 0 & 0 \\
\hline$\#$ & 0 & 0 & 1 & 3 & 9 & 11 & 1 \\
\hline
\end{tabular}

\begin{tabular}{ccccccll}
\hline \multicolumn{1}{c}{ Group R2.7 } \\
\hline & \multicolumn{7}{c}{$p_{t}$} \\
$n_{t+1}$ & 6 & 5 & 4 & 3 & 2 & 1 & 0 \\
\hline 6 & 0 & & 0 & 0 & 0 & 0.11 & \\
5 & 0 & & 0 & 0 & 0 & 0 & \\
4 & 1 & & 0 & 0 & 0 & 0.44 & \\
3 & 0 & & 1 & 0 & 0 & 0.11 & \\
2 & 0 & & 0 & 1 & 0 & 0 & \\
1 & 0 & & 0 & 0 & 1 & 0.33 & \\
0 & 0 & & 0 & 0 & 0 & 0 & \\
\hline$\#$ & 1 & 0 & 5 & 5 & 5 & 9 & 0 \\
\hline
\end{tabular}

\begin{tabular}{|c|c|c|c|c|c|c|c|}
\hline \multicolumn{8}{|c|}{ Group R2.11 } \\
\hline \multirow[b]{2}{*}{$p_{t+1}$} & \multicolumn{7}{|c|}{$p_{t}$} \\
\hline & 6 & 5 & 4 & 3 & 2 & 1 & 0 \\
\hline 6 & & 0 & & 0 & 0 & 0 & \\
\hline 5 & & 0 & & 0 & 0 & 0.08 & \\
\hline 4 & & 0 & & 0 & 0 & 0 & \\
\hline 3 & & 1 & & 0 & 0 & 0.08 & \\
\hline 2 & & 0 & & 1 & 0.60 & 0.23 & \\
\hline 1 & & 0 & & 0 & 0.40 & 0.62 & \\
\hline 0 & & 0 & & 0 & 0 & 0 & \\
\hline \# & 0 & 1 & 0 & 1 & 10 & 13 & 0 \\
\hline
\end{tabular}

Table 3: Probability that $p_{t+1}$ is set conditional on $p_{t}$ after period 14 .

equilibrium, prices are brought up to 5 and coordination takes place at a price of 0 . A reason for the coordination to take place at price 1 may be that undercutting to 0 would induce zero profit for at least two periods, whereas matching at 1 results in a profit of at least 2.5 over these two periods.

In the other four observations that do not coordinate at a common price, no real cyclical behavior is observed over the mature periods. In Groups R1.6, R2.5, and R2.6 undercutting mainly takes place before period 28. Moreover, in these groups and in Group R2.11 prices fluctuate between 0 and 3 or between 1 and 3 instead of cycling within these intervals.

To summarize, for 20 of the 27 observations, the subjects' behavior is consistent with the focal price equilibrium, possibly after some learning. Cyclical behavior is only found in one observation: Group R2.7. The remaining six observations are difficult to classify as 
being in line with either the focal price equilibrium or the equilibrium involving price cycles. Among these there are two observations where the price settled at 2. Although this is not an equilibrium, there is some logic behind prices stabilizing at 2. In comparison with the focal price equilibrium, the immediate benefit from undercutting the other firm is much lower, while the resulting per period profit is only a halve lower. Moreover, it would take (at least) eight periods, to compensate for the immediate loss of inducing a switch to the focal price.

\subsection{Fixed ending}

For this treatment we have 15 independent observations that are gathered in one single session. Within this session, subjects interacted in pairs for 80 periods. The only behavior that is consistent with common belief of rationality results in the cyclical price pattern of Figure 4. So, unlike for the treatment with random ending, there is no (subgame-perfect) equilibrium with prices settling down at 3 . Nevertheless, in experiments with long time horizons behavior is often observed to be more in line with an infinite than with a finite horizon until shortly before the end. ${ }^{7}$ Hence, in line with the previous subsection, observations with prices constant at 3 are not unlikely. All decisions made throughout this session are presented in Appendix B.

In ten out of the 15 groups, subjects coordinated on a common price. One of these ten groups (Group F.13) settled down at a price of 2, the other nine at a price of 3 . From the latter nine, seven of groups managed to coordinate on one price within 10 periods. The other two groups needed more than 25 periods. In all observations where prices stabilized at some point, an endgame effect with length of at most three periods is observed. To be precise, in two observations there is an endgame effect of length one, in five observations of length two, and in three observations of length three. This signals that subjects seemed to apply the procedure of backwards induction only when the end of the session was near, and not earlier.

The other five groups (Groups F.2, F.7, F.8, F.9 and F.10) seem to behave more in line with the notion of common belief in sequential rationality. In order to see how close these groups matched equilibrium behavior, we study the dynamics of their pricing behavior in more detail. Table 4 displays for each group the conditional switching probabilities for the observations after period 15 and before period 74. Each entry in the table shows the probability that a current price of $p_{t}$ is followed by a price of $p_{t+1}$ in the subsequent period. The last row shows the number of observations on which the probabilities are based for each of the possible current prices.

In Group F.7 the price never got above 3. In the other observations the price quickly declined towards 3 when it was above it. A price of 3 was undercut with certainty in Groups F.2 and F.10, and with 0.78 probability in Group F.9. In Groups F.7 and F.8 a price of 3 was matched with high probability, but this price stability is most prominent in the periods between 15 and 45. In all groups a price of 2 was likely to be followed by a price of 1 , although in quite

\footnotetext{
${ }^{7}$ See for instance Selten and Stoecker (1986), Engle-Warnick and Slonim (2004), and Normann and Wallace (2006).
} 


\begin{tabular}{cccccllll}
\hline \multicolumn{8}{c}{ Group F.2 } \\
\hline & \multicolumn{7}{c}{$p_{t}$} \\
\cline { 2 - 8 }$p_{t+1}$ & 6 & 5 & 4 & 3 & 2 & 1 & 0 \\
\hline 6 & 0 & & 0 & 0 & 0 & 0.14 & \\
5 & 0 & & 0 & 0 & 0 & 0 & \\
4 & 0 & & 0 & 0 & 0 & 0.07 & \\
3 & 1 & & 1 & 0 & 0.18 & 0.04 & \\
2 & 0 & & 0 & 1 & 0.35 & 0.04 & \\
1 & 0 & & 0 & 0 & 0.47 & 0.71 & \\
0 & 0 & & 0 & 0 & 0 & 0 & \\
\hline$\#$ & 4 & 0 & 2 & 9 & 17 & 28 & 0 \\
\hline
\end{tabular}

\begin{tabular}{ccccccccc}
\hline \multicolumn{7}{c}{ Group F.7 } \\
\hline & \multicolumn{7}{c}{$p_{t}$} \\
\cline { 2 - 8 }$p_{t+1}$ & 6 & 5 & 4 & 3 & 2 & 1 & 0 \\
\hline 6 & & & & 0 & 0 & 0 & \\
5 & & & & 0 & 0 & 0 & \\
4 & & & & 0 & 0 & 0 & \\
3 & & & & 0.73 & 0 & 0.23 & \\
2 & & & & 0.23 & 0.25 & 0 & \\
1 & & & & 0.04 & 0.75 & 0.77 & \\
0 & & & & 0 & 0 & 0 & \\
\hline$\#$ & 0 & 0 & 0 & 26 & 8 & 26 & 0 \\
\hline
\end{tabular}

\begin{tabular}{clllllll}
\hline \multicolumn{10}{c}{ Group F.8 } \\
\hline & \multicolumn{7}{c}{$p_{t}$} \\
\cline { 2 - 8 }$p_{t+1}$ & 6 & 5 & 4 & 3 & 2 & 1 & 0 \\
\hline 6 & 0 & 0 & 0 & 0 & 0 & 0.17 & 0 \\
5 & 0 & 0 & 0 & 0 & 0.20 & 0.08 & 0 \\
4 & 0 & 0 & 0 & 0.03 & 0 & 0 & 0 \\
3 & 1 & 1 & 1 & 0.78 & 0 & 0 & 1 \\
2 & 0 & 0 & 0 & 0.19 & 0.40 & 0 & 0 \\
1 & 0 & 0 & 0 & 0 & 0.40 & 0.67 & 0 \\
0 & 0 & 0 & 0 & 0 & 0 & 0.08 & 0 \\
\hline$\#$ & 1 & 3 & 1 & 32 & 10 & 12 & 1 \\
\hline
\end{tabular}

\begin{tabular}{clllllll}
\hline \multicolumn{10}{c}{ Group F.9 } \\
\hline & \multicolumn{7}{c}{$p_{t}$} \\
\cline { 2 - 8 }$p_{t+1}$ & 6 & 5 & 4 & 3 & 2 & 1 & 0 \\
\hline 6 & 0 & 0 & 0 & 0 & 0 & 0.19 & \\
5 & 0.60 & 0 & 0 & 0 & 0 & 0.08 & \\
4 & 0 & 1 & 0 & 0 & 0 & 0 & \\
3 & 0.40 & 0 & 1 & 0.22 & 0 & 0 & \\
2 & 0 & 0 & 0 & 0.78 & 0 & 0.08 & \\
1 & 0 & 0 & 0 & 0 & 1 & 0.65 & \\
0 & 0 & 0 & 0 & 0 & 0 & 0 & \\
\hline$\#$ & 5 & 6 & 5 & 9 & 9 & 26 & 0 \\
\hline
\end{tabular}

\begin{tabular}{clllllll}
\hline \multicolumn{10}{c}{ Group F.10 } \\
\hline & \multicolumn{1}{c}{$p_{t}$} \\
\cline { 2 - 8 }$p_{t+1}$ & 6 & 5 & 4 & 3 & 2 & 1 & 0 \\
\hline 6 & 0 & 0 & 0 & 0 & 0 & 0.06 & 0.17 \\
5 & 1 & 0.13 & 0 & 0 & 0.10 & 0 & 0.67 \\
4 & 0 & 0.88 & 0 & 0 & 0 & 0 & 0.17 \\
3 & 0 & 0 & 1 & 0 & 0 & 0.06 & 0 \\
2 & 0 & 0 & 0 & 1 & 0.10 & 0 & 0 \\
1 & 0 & 0 & 0 & 0 & 0.80 & 0.53 & 0 \\
0 & 0 & 0 & 0 & 0 & 0 & 0.35 & 0 \\
\hline$\#$ & 2 & 8 & 8 & 9 & 10 & 17 & 6 \\
\hline
\end{tabular}

Table 4: Probability that $p_{t+1}$ is set conditional on $p_{t}$ after period 14 and before period 75 .

some cases the price of 2 was matched. Once the price was 1, with high probability the price was either matched or (substantially) brought up. In Group F.10 the price frequently further decreased to 0 , before being brought up.

The switching probabilities indicate that the price dynamics in Groups F.2, F.9 and F.10 seem to follow the subgame-perfect equilibrium prediction closely. Also, the mode price being equal to 1, is in line with the equilibrium prediction. In Groups F.7 and F.8, another kind of cycle is observed. Prices are rather stable at 3 , with only a small probability on an undercut. At some point, an undercut takes place and is likely to be followed by another undercut. Next, the price stabilizes at 1 , until it is brought up in order to stabilize once more at 3 . This pricing pattern has the structure of the classical price war of alternations between periods of gentle and periods of severe price competition. 
To summarize, nine of the 15 groups behave according to the focal price equilibrium of the infinite horizon counterpart. Of the remaining five observations, three observations clearly display price cycles. The other two show cyclical behavior that is comparable to that of the classical price war.

\section{Discussion}

We experimentally analyzed the alternating price setting duopoly of Maskin and Tirole (1988). When this game is played for an infinite number of periods, two Markov perfect equilibria coexist; one consisting of a focal price and one consisting of Edgeworth cycles. We find that the focal price equilibrium emerges in 20 out of 27 observations. Only in a single observation subjects' behavior displays price cycles.

We also analyze the alternating price setting game in case the number of periods is fixed. We find that the subgame-perfect equilibrium consists of prices that cycle. Experimentally, we still observe the focal price in nine out of 15 observations, even though this is not a subgame-perfect equilibrium. Of the remaining five observations, three clearly display price cycles. The other two observations show cyclical behavior that is comparable to that of the classical price war. Consequently, there is less cooperative behavior in the treatment with fixed ending than in the treatment with random ending, although it is impossible to validate this by means of statistical tests.

It has been difficult to find undercutting behavior, and hence price cycles, in the laboratory so far. Especially for settings with few players there had been no experimental observations of them. In our experiments we were able to find cycling prices in a dynamic setting with only two players, although in the majority of the cases the players coordinated on a single price. The pricing behavior in the latter instances can, however, not be distinguished from collusive behavior - something that is not unlikely to be found in experiments with just two players interacting. Nevertheless, we can conclude that the alternating move structure (that is, short-run price commitments) has the potential to enhance undercutting behavior and hence to induce price cycles.

Even though it is quite a strong result to find cycling prices for the present setting, future research is needed to see whether prices cycle more often if some of the settings of the alternating move game are changed. For instance, the number of players and hence the number of periods for which prices are committed could be increased. Furthermore, the addition of exogenous demand shocks would make undercutting in periods of high demand more profitable and hence could lead to more cycling behavior. Finally, the structure of the profit table could be altered to make undercutting the focal price more profitable, although the coexistence of the two equilibria needs to be retained. 


\section{References}

1. Bertrand, J. (1883). Review of theorie mathematique de la richesse sociale and recherches sur les principes mathematicque de la theoire des richesse. Journal des Savants, 67, 499508.

2. Brandts J. and P. Guillén (2006). Collusion and fights in an experiment with pricesetting firms and production in advance. Journal of Industrial Economics, forthcoming.

3. Busse, M. (2002). Firm financial condition and airline price wars. The RAND Journal of Economics, 33 (2), 298-318.

4. Cason, T.N., D. Friedman, and F. Wagener (2003). The dynamics of price dispersion, or Edgeworth variations. Journal of Economic Dynamics and Control, 29 (4), 801-822.

5. Castanias, R. and H. Johnson (2001). Gas wars: Retail gasoline price fluctuations. The Review of Economics and Statistics, 75 (1), 171-174.

6. Chamberlain, E. (1933). The theory of monopolistic competition. Harvard university Press, Massachusetts.

7. Dal Bó, P. (2005). Cooperation under the shadow of the future: Experimental evidence from infinitely repeated games. The American Economic Review, 95 (5), 1591-1604.

8. Doyle, J., E. Muehlegger, and K. Samphantharak (2007). Market concentration and Edgeworth cycles in gasoline markets. Working paper.

9. Eckert, A. (2003). Retail price cycles and the presence of small firms. International Journal of Industrial Organization, 21 (2), 151-170.

10. Edgeworth, F.Y. (1925). The pure theory of monopoly. In: Papers Relating to Political Economy, London: MacMillan, pp. 111-142.

11. Fischbacher, U. (2007). z-Tree: Zurich toolbox for ready-made economic experiments. Experimental Economics, 10 (2), 171-178.

12. Green, E. and R. Porter (1984). Non-cooperative collusion under imperfect price information. Econometrica, 52 (1), 87-100.

13. Guillén, P. (2004). Price-quantity competition and Edgeworth cycles. Working paper, Universitat Autónoma de Barcelona.

14. Hall, R. and C. Hitch (1939). Price theory and business behavior. Oxford Economic Papers, 2, 12-45. 
15. Kruse, J.B., S. Rassenti, S.S. Reynolds, and V.L. Smith (1994). Bertrand-Edgeworth competition in experimental markets. Econometrica, 62 (2), 343-371.

16. Lewis, M.S. (2008). Temporary wholesale gasoline price spikes have long-lasting retail effects: The aftermath of hurricane Rita. Journal of Law and Economics, forthcoming.

17. Maskin, E. and J. Tirole (1988). A theory of dynamic oligopoly II: Price competition, kinked demand curves and Edgeworth cycles Econometrica, 56 (3), 571-599.

18. Noel, M.D. (2007). Edgeworth price cycles, cost-based pricing, and sticky pricing in retail gasoline markets. Review of Economics and Statistics, 89 (2), 324-334.

19. Ross, L.B. (1997). When will an airline stand its ground? An analysis of fare wars. International Journal of the Economics of Business, 4 (2), 109-127.

20. Rotemberg, J. and G. Saloner (1986). A supergame-theoretic model of business cycles and price wars during booms. The American Economic Review, 76 (3), 390-407.

21. Selten, R., M. Mitzkewitz, and G.R. Uhlich (1997). Duopoly strategies programmed by experienced players. Econometrica, 65 (3), 517-555.

22. Sweezy, P. (1939). Demand under conditions of oligopoly. Journal of Political Economy, $47(4), 568-573$.

23. Wang Z. (2005). Strategy, timing and oligopoly pricing: Evidence from a repeated game in a timing-controlled gasoline market. Working paper, Northeastern University, Boston. 


\section{A Treatments with random ending}

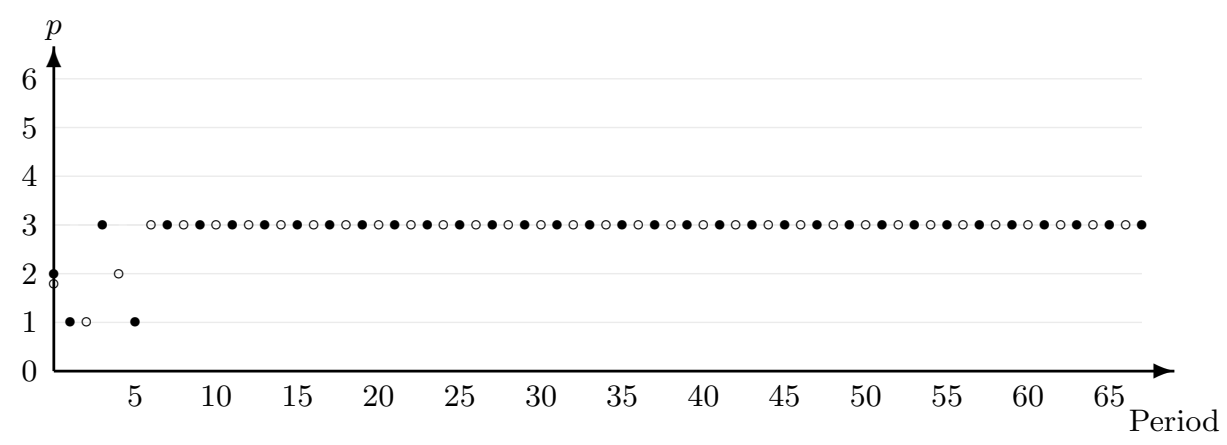

Figure 5: Group R1.1

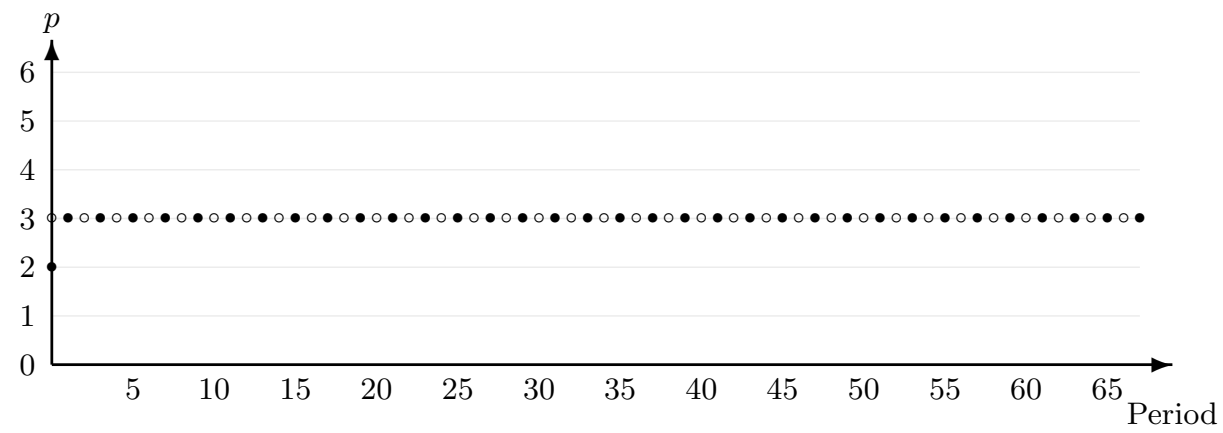

Figure 6: Group R1.2

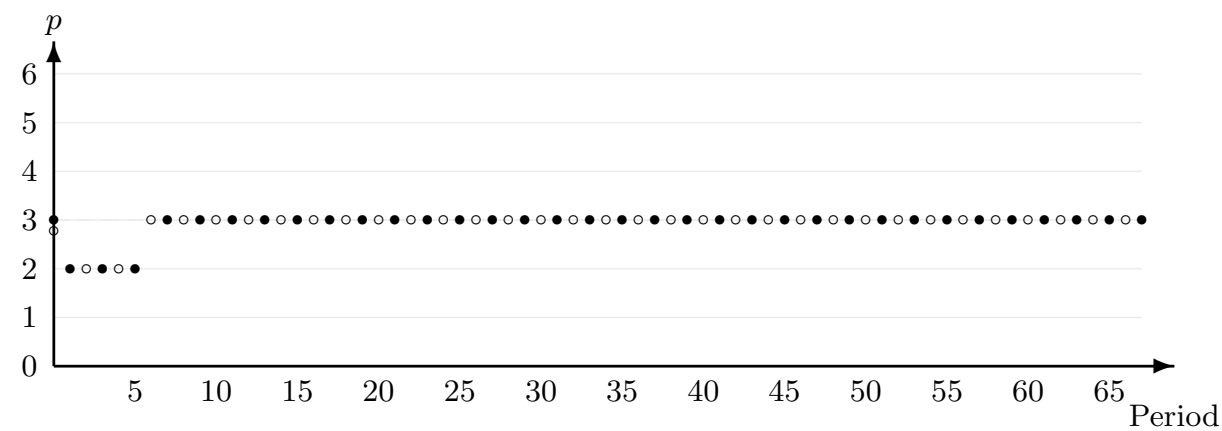

Figure 7: Group R1.3

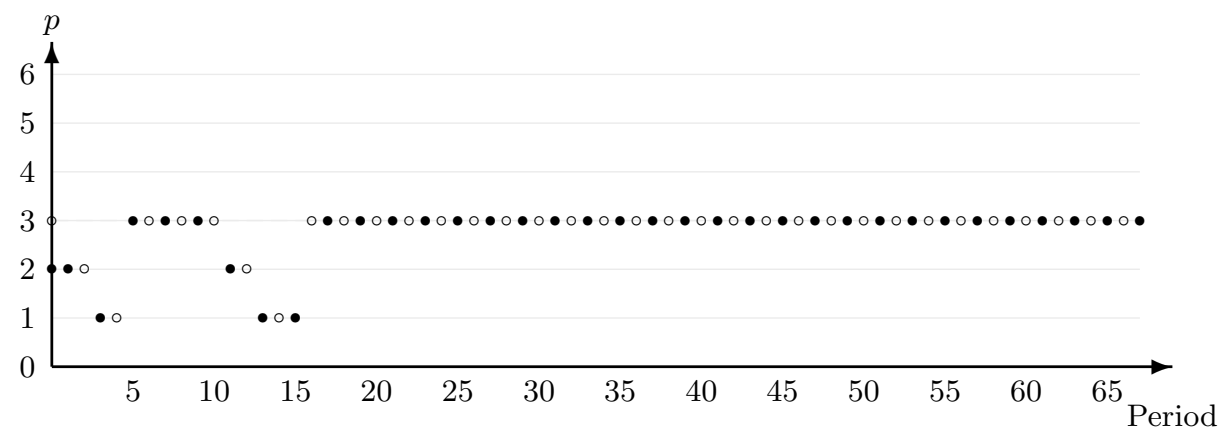

Figure 8: Group R1.4 


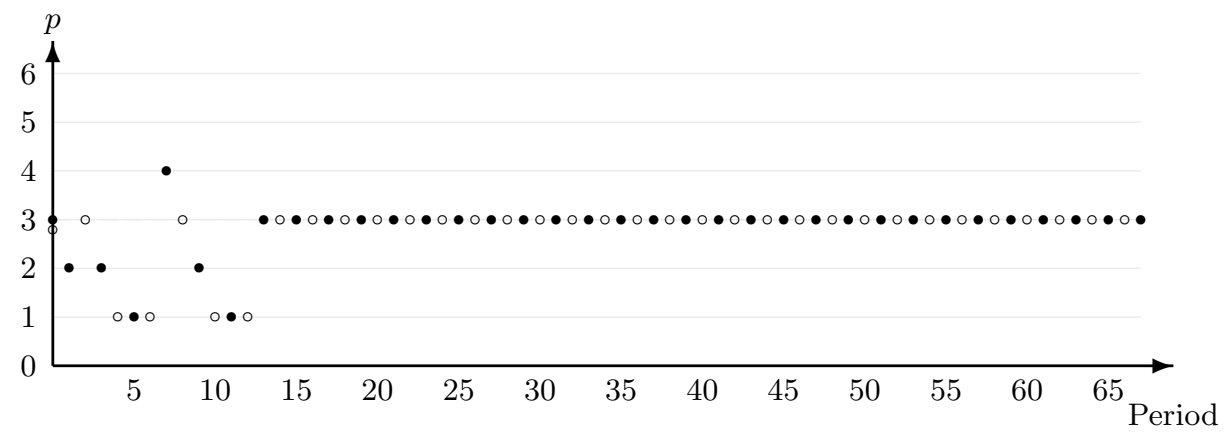

Figure 9: Group R1.5

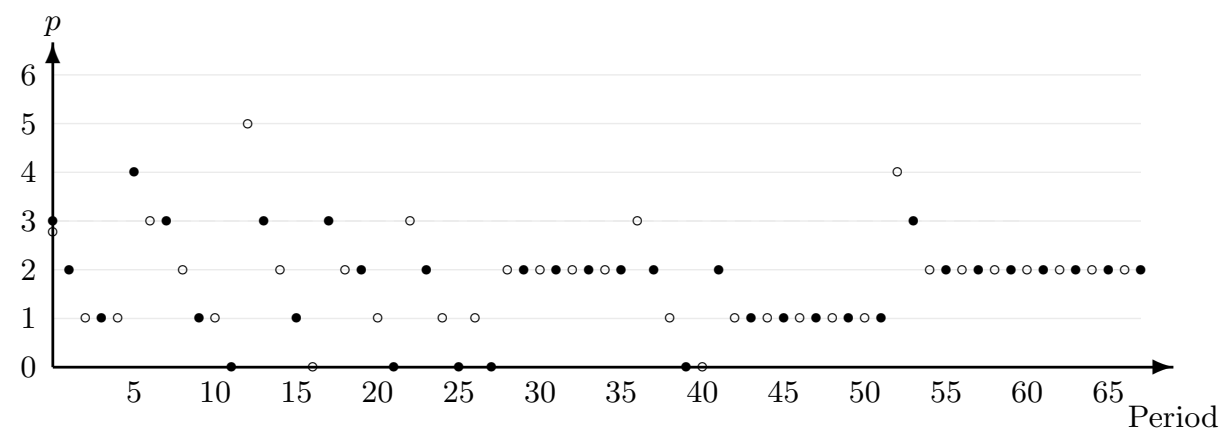

Figure 10: Group R1.6

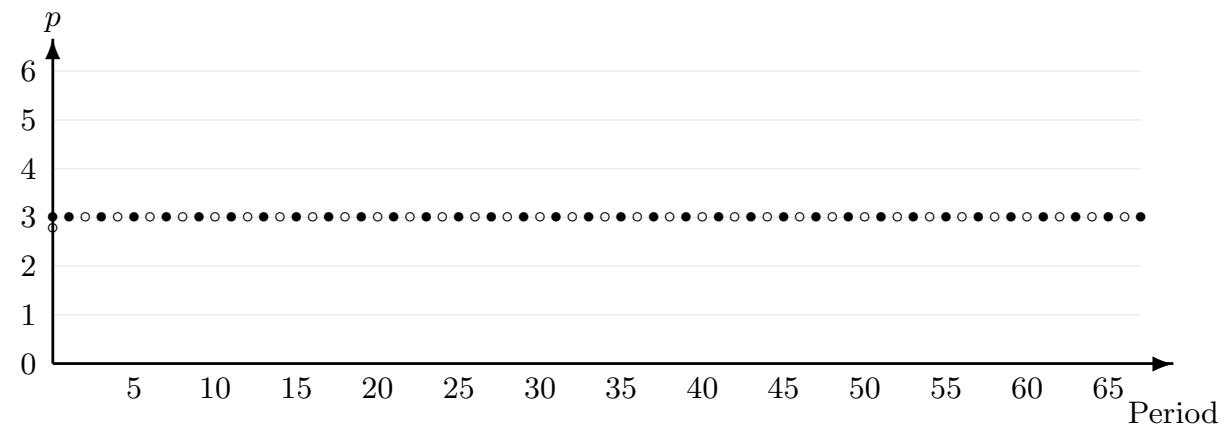

Figure 11: Group R1.7

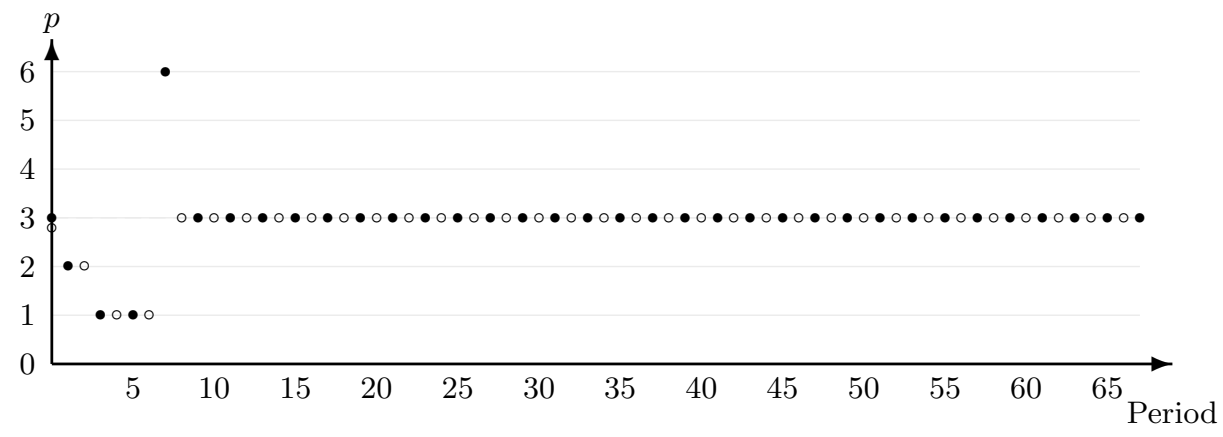

Figure 12: Group R1.8 


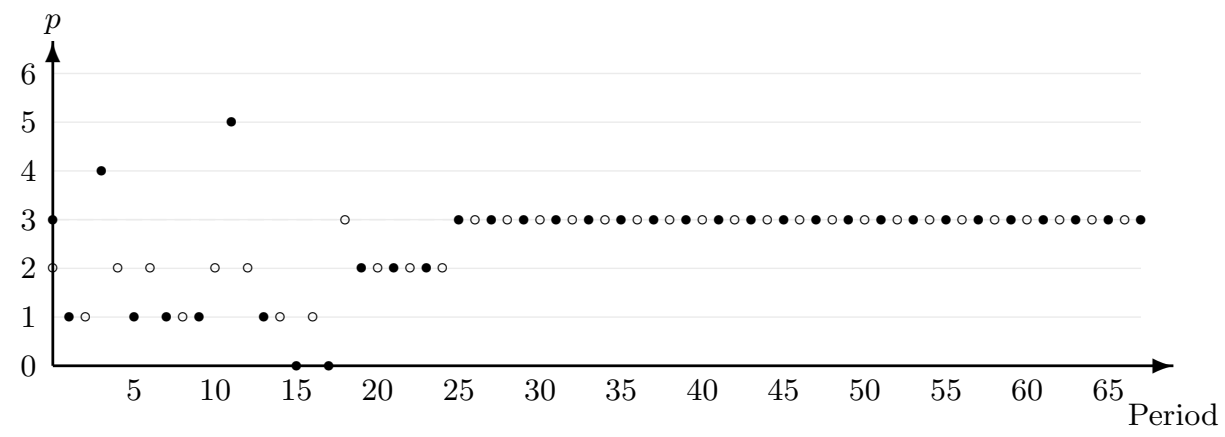

Figure 13: Group R1.9

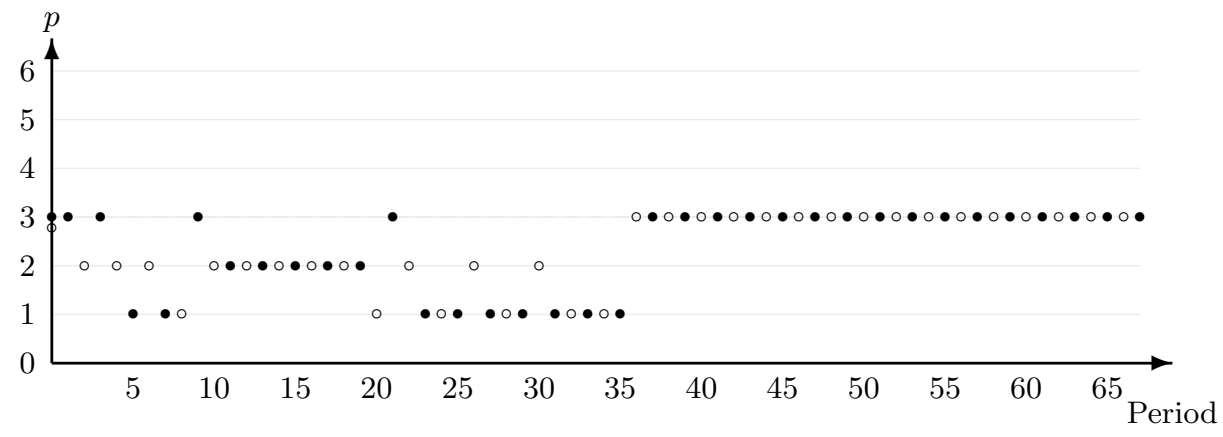

Figure 14: Group R1.10

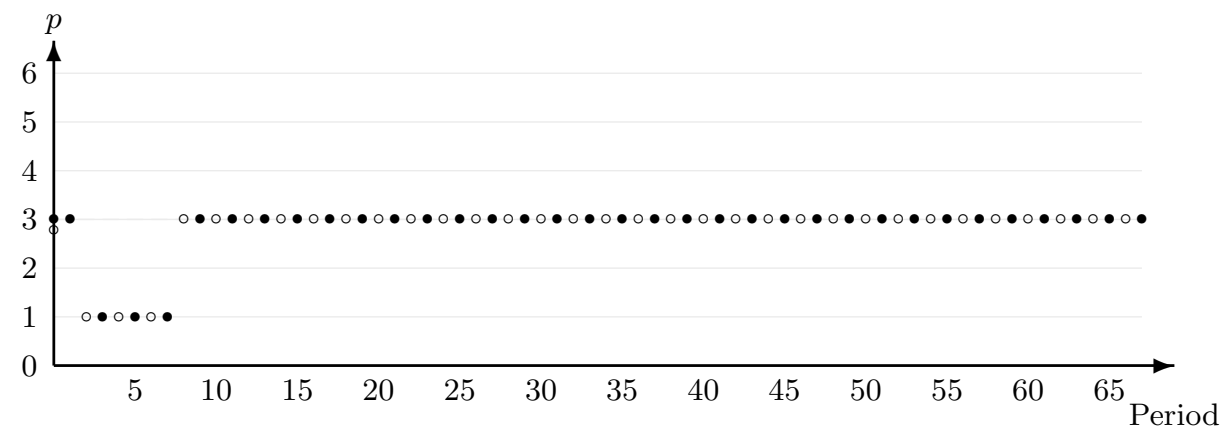

Figure 15: Group R1.11

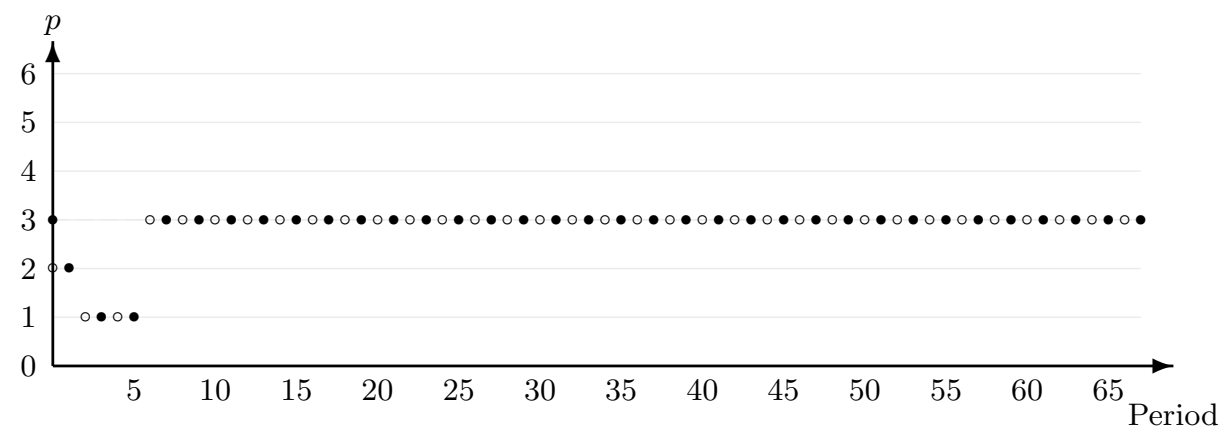

Figure 16: Group R1.12 


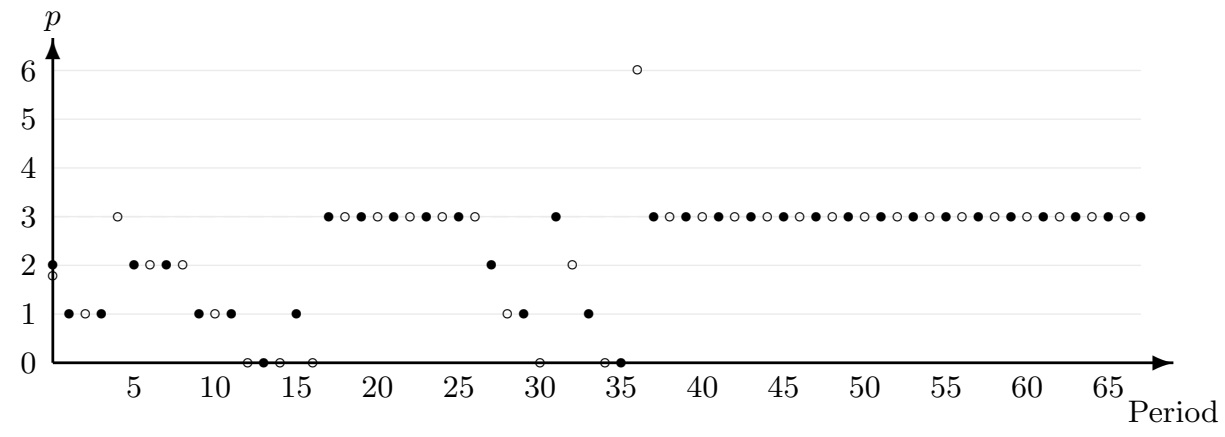

Figure 17: Group R1.13

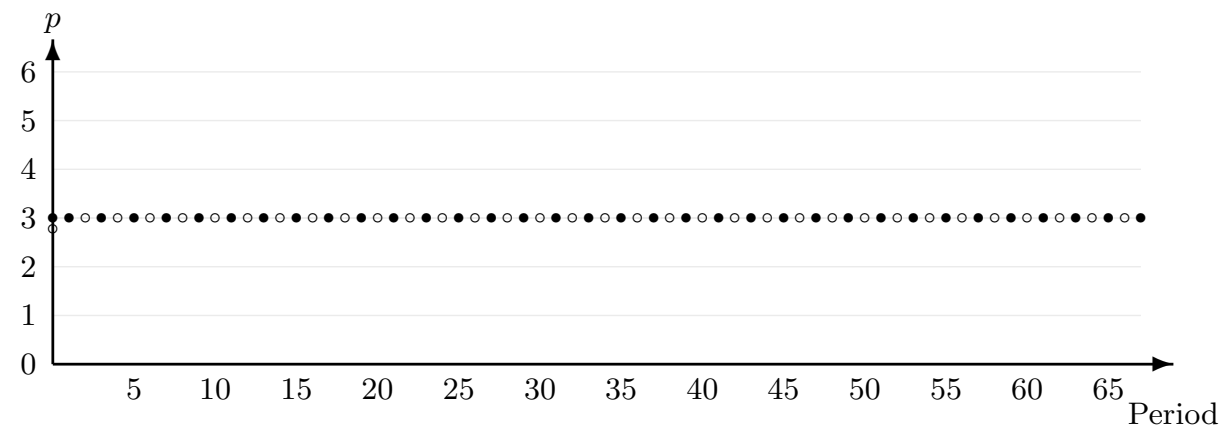

Figure 18: Group R1.14

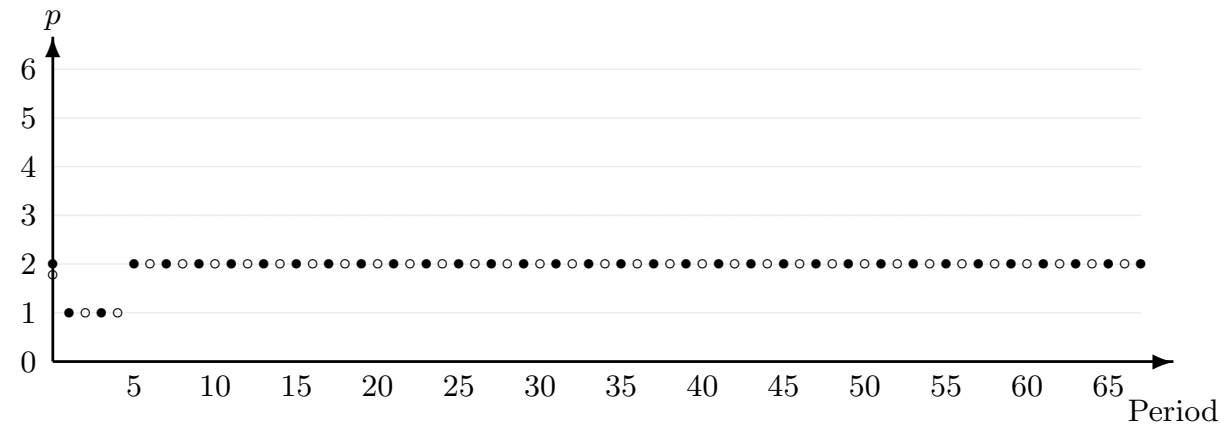

Figure 19: Group R1.15

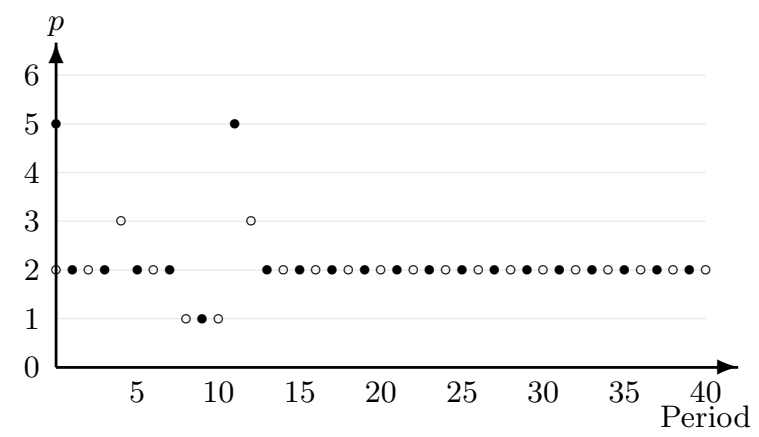

Figure 20: Group R2.1

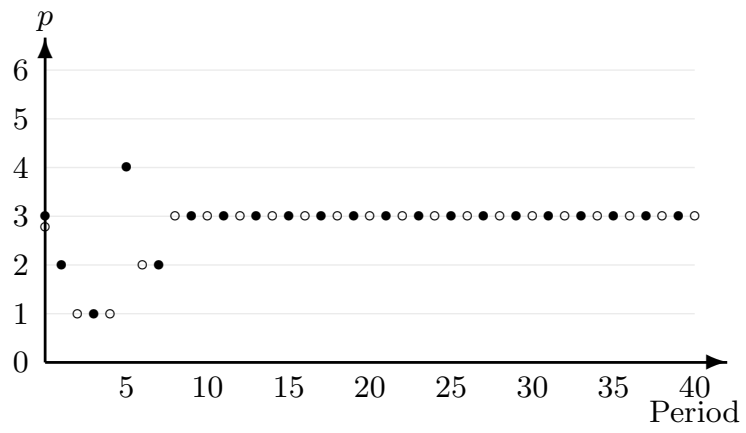

Figure 21: Group R2.2 


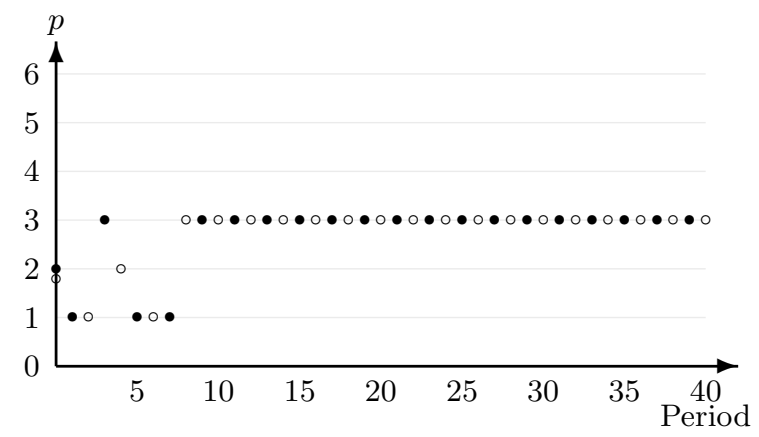

Figure 22: Group R2.3

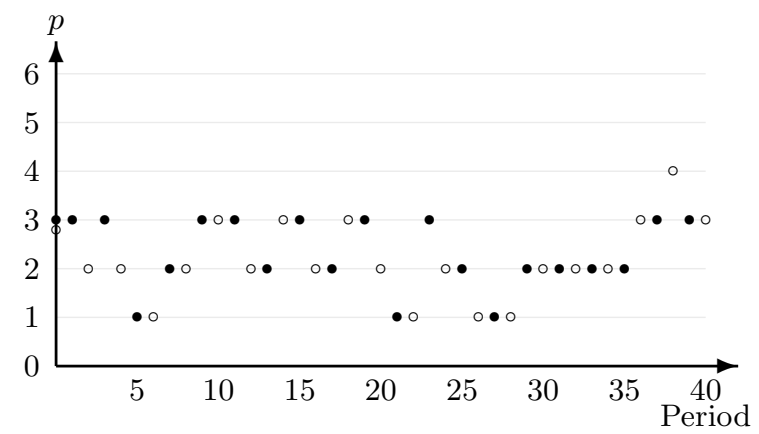

Figure 24: Group R2.5

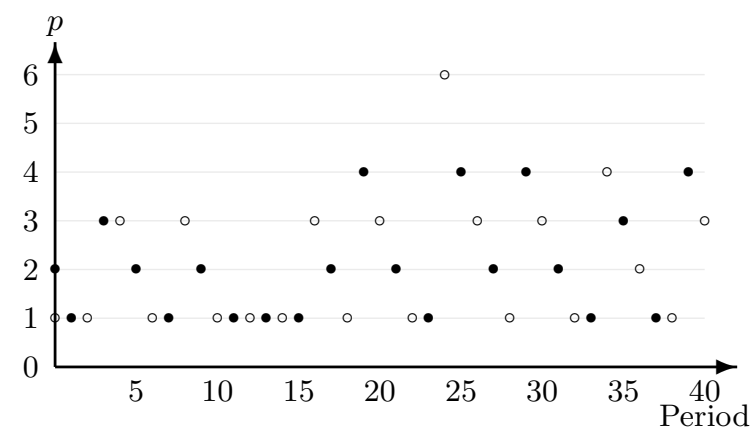

Figure 26: Group R2.7

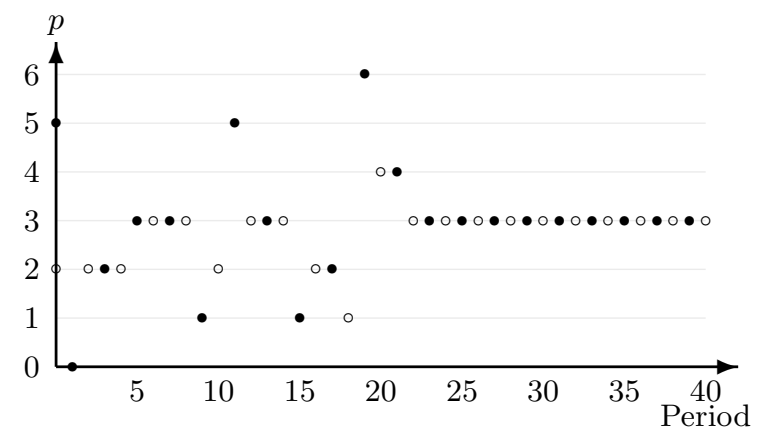

Figure 28: Group R2.9

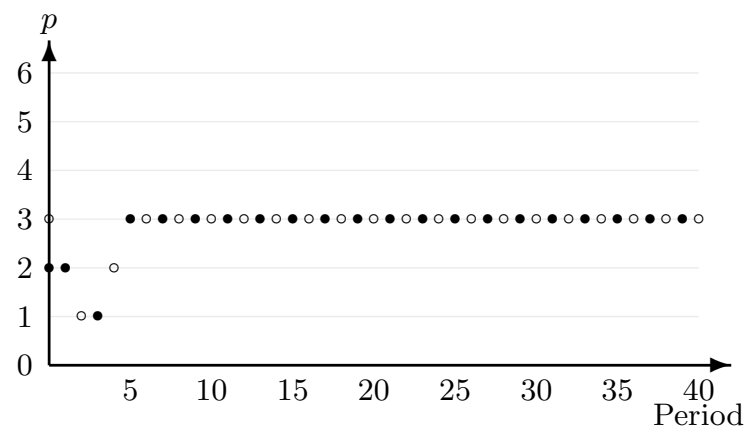

Figure 23: Group R2.4

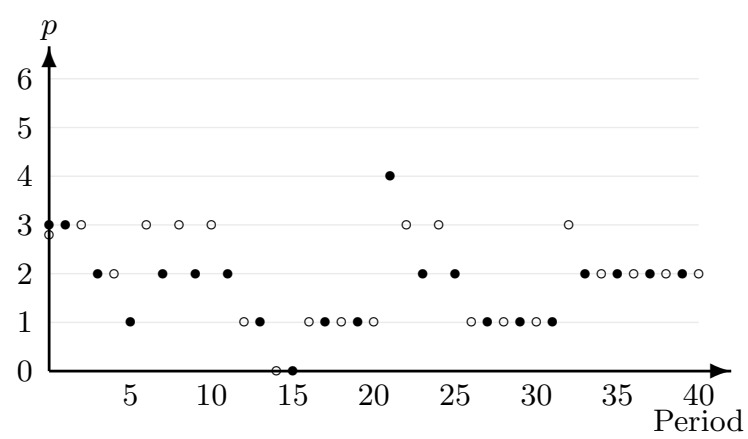

Figure 25: Group R2.6

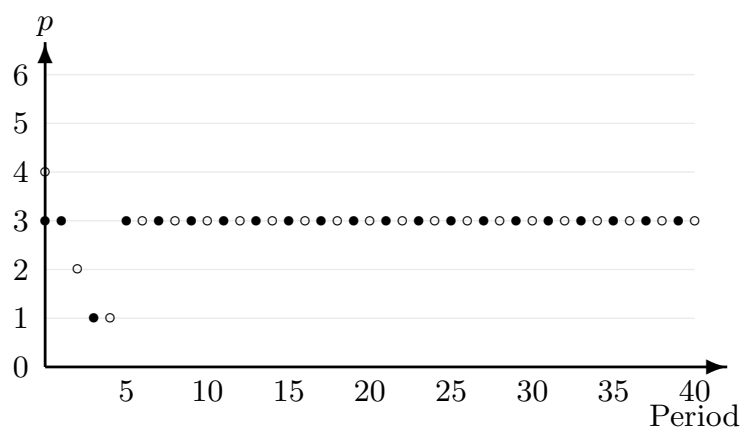

Figure 27: Group R2.8

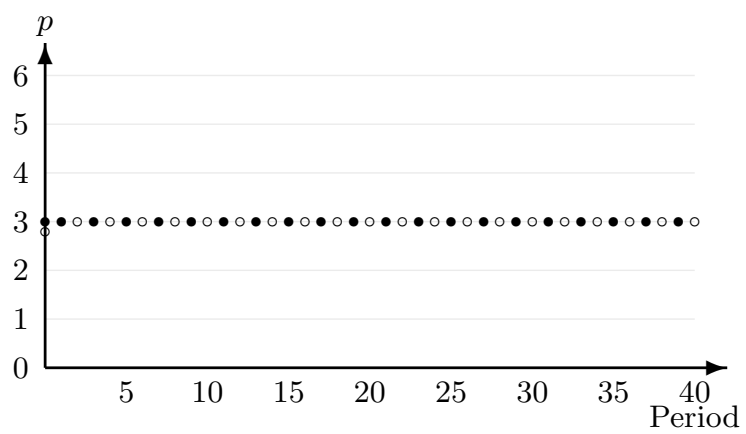

Figure 29: Group R2.10 


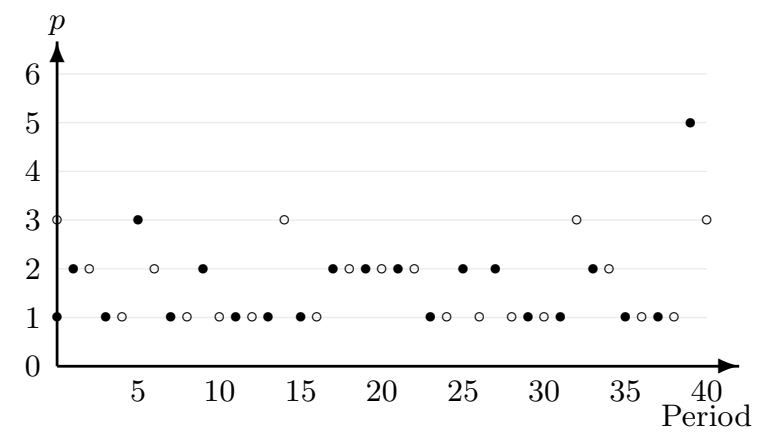

Figure 30: Group R2.11

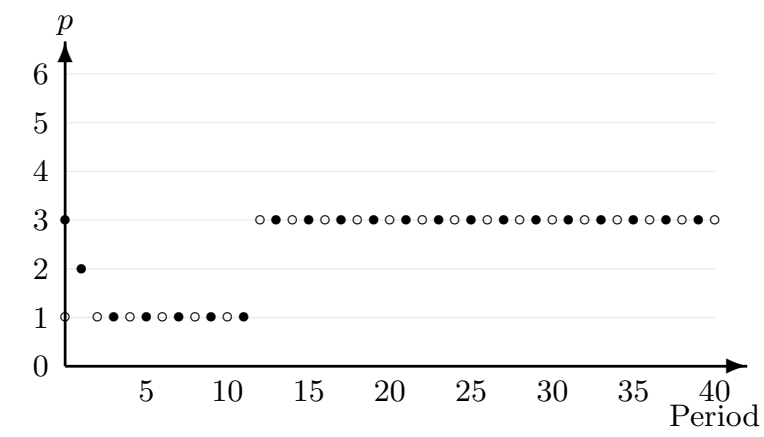

Figure 31: Group R2.12

\section{B Treatment with fixed ending}

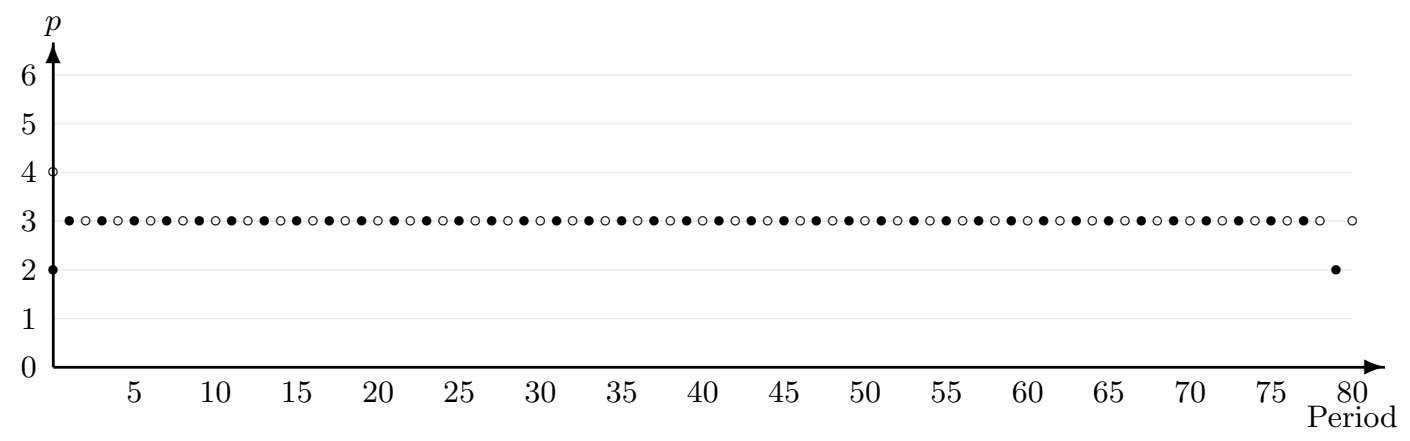

Figure 32: Group F.1

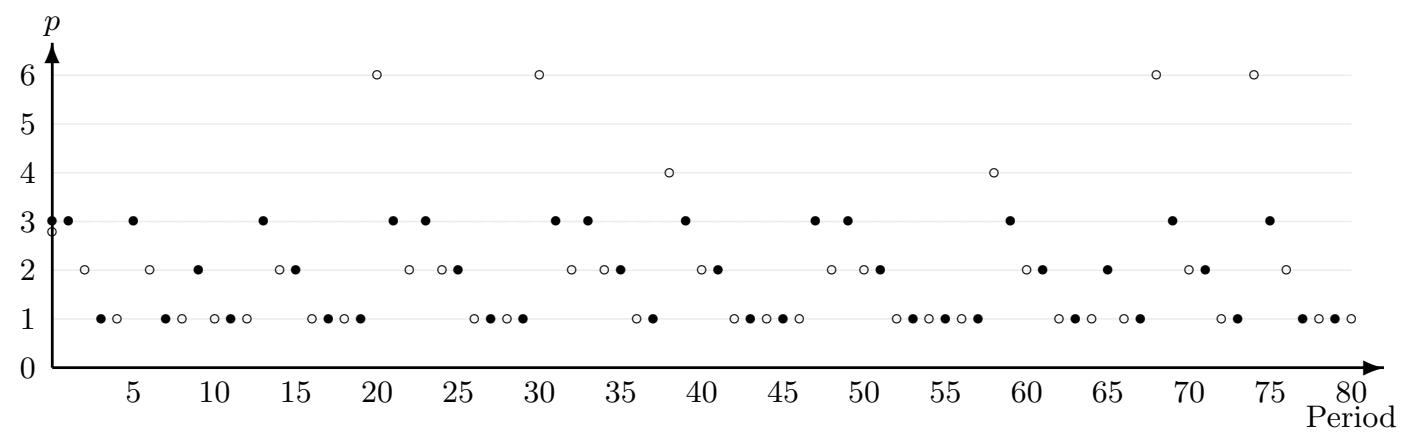

Figure 33: Group F.2

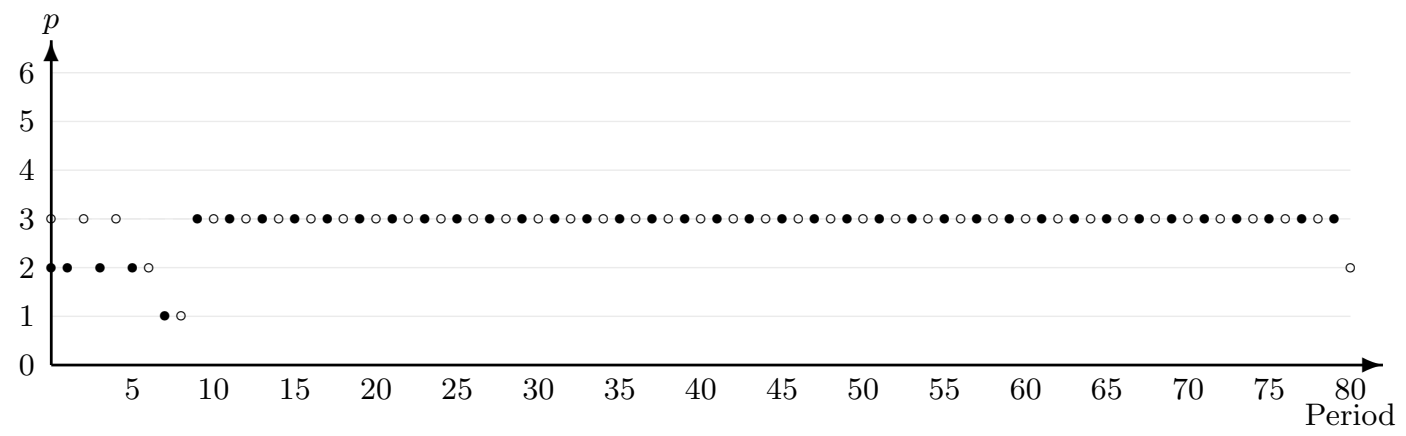

Figure 34: Group F.3 


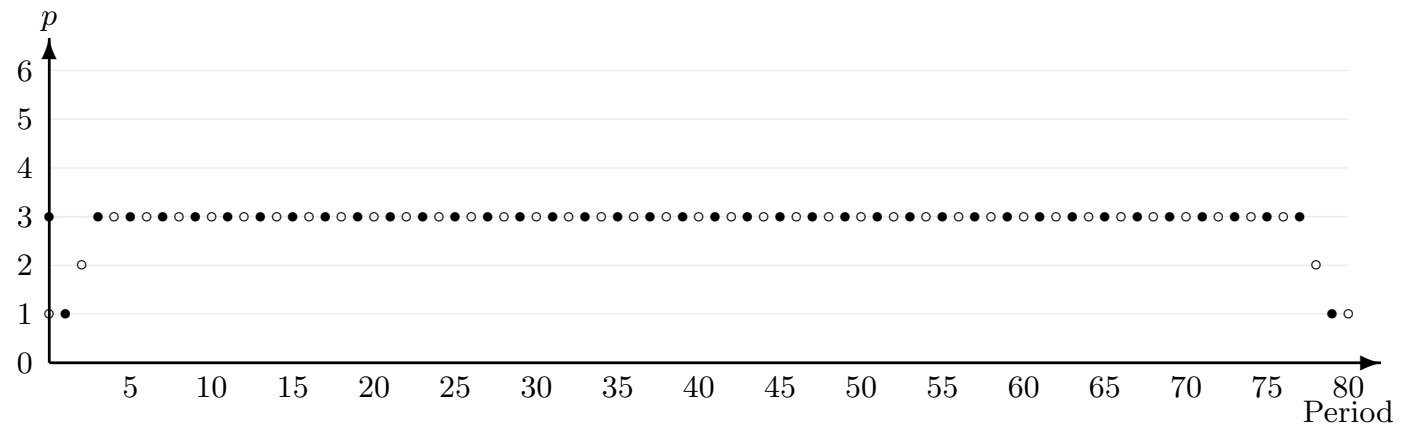

Figure 35: Group F.4

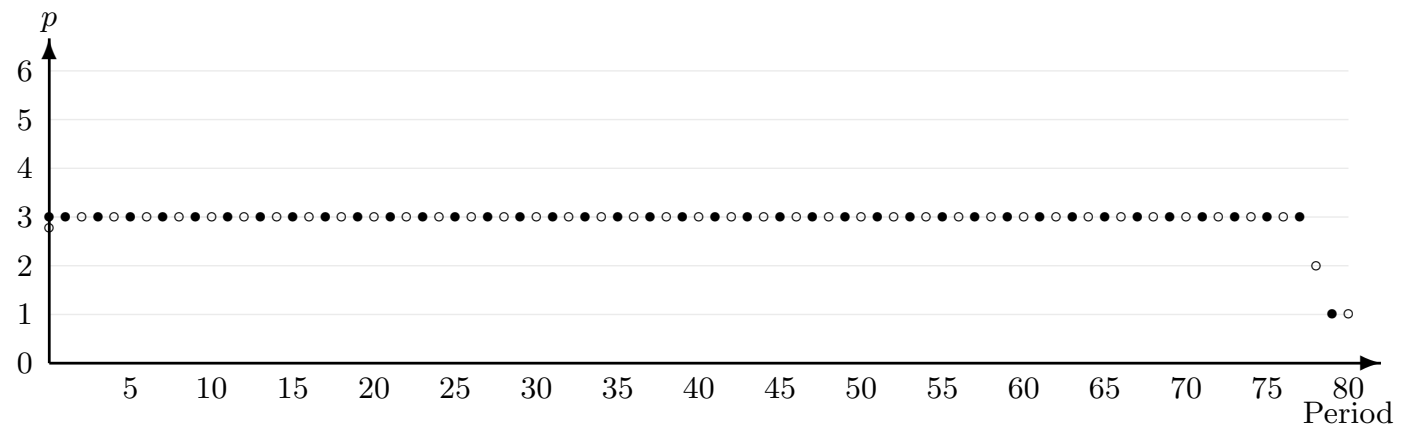

Figure 36: Group F.5

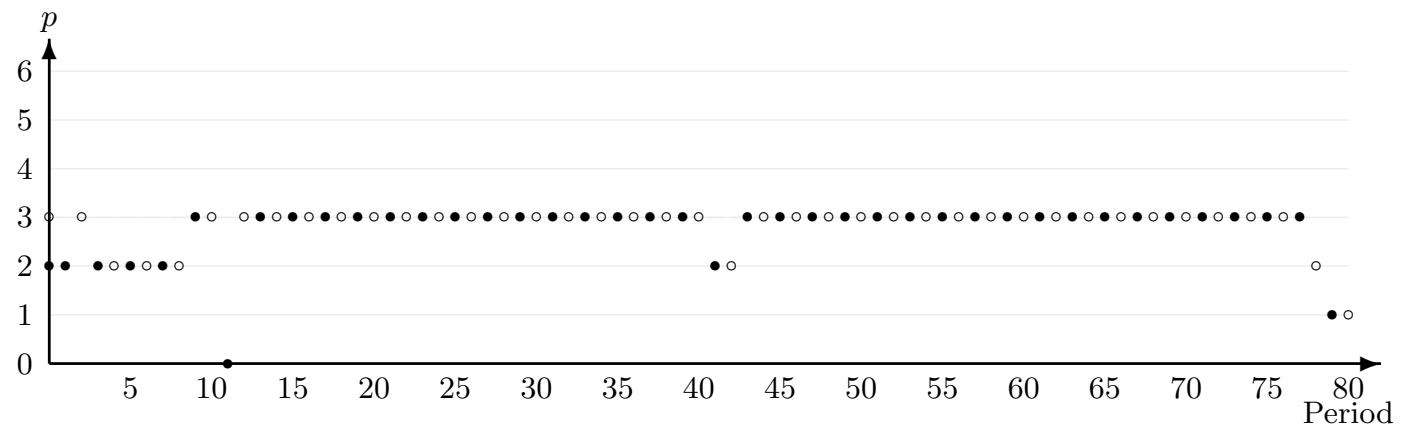

Figure 37: Group F.6

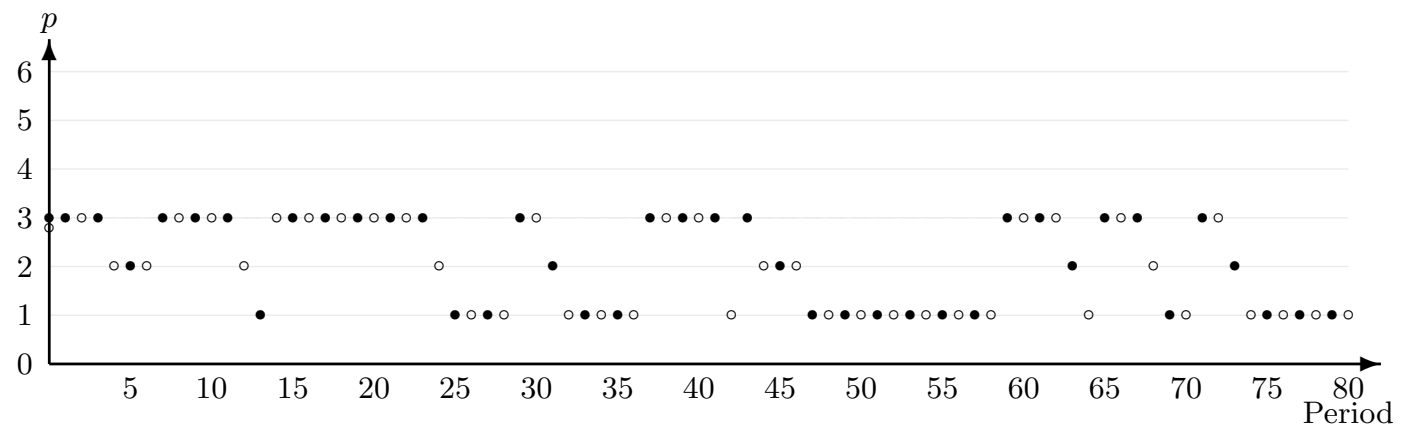

Figure 38: Group F.7 


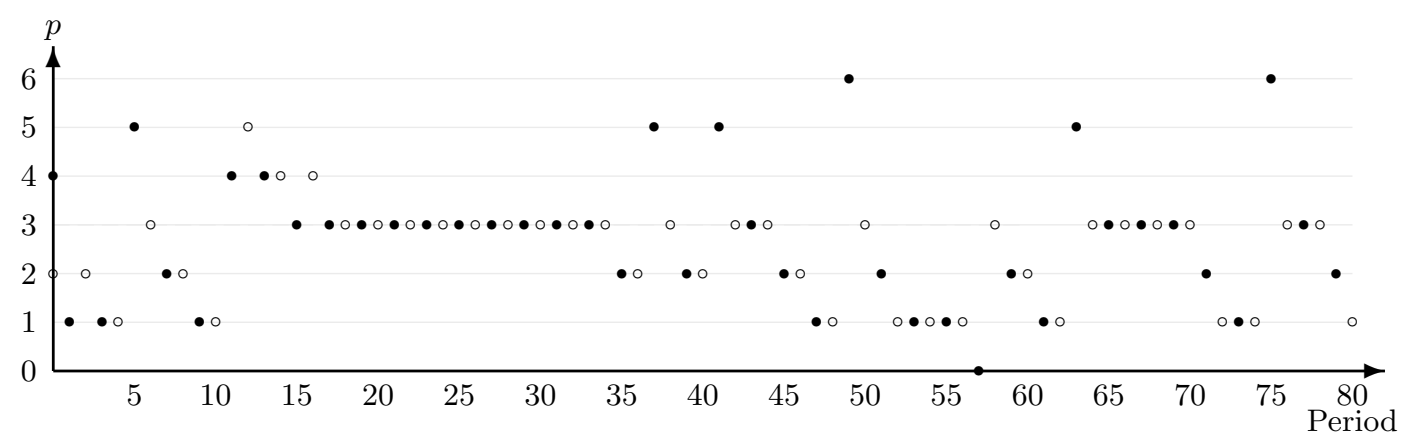

Figure 39: Group F.8

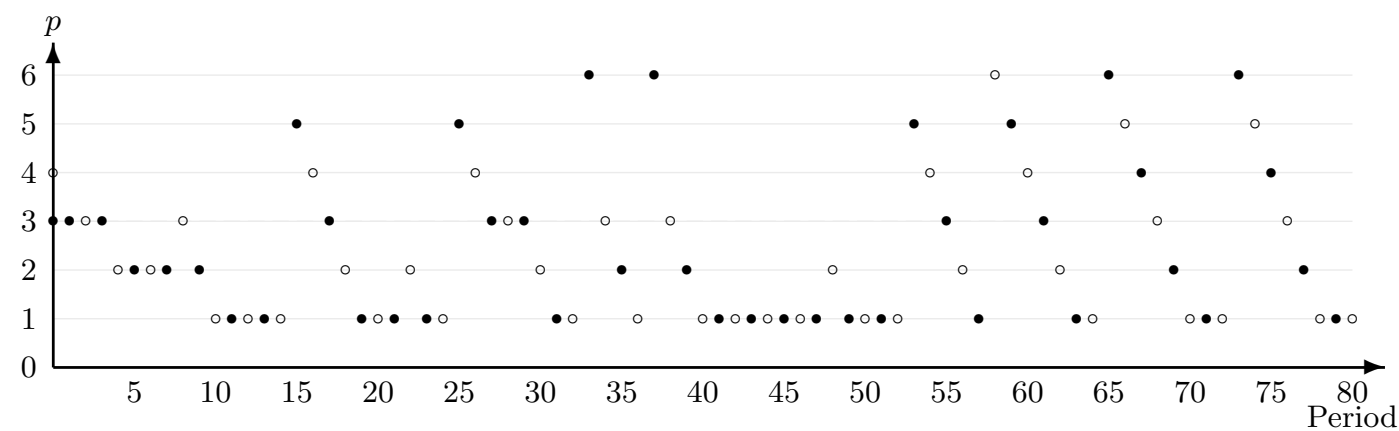

Figure 40: Group F.9

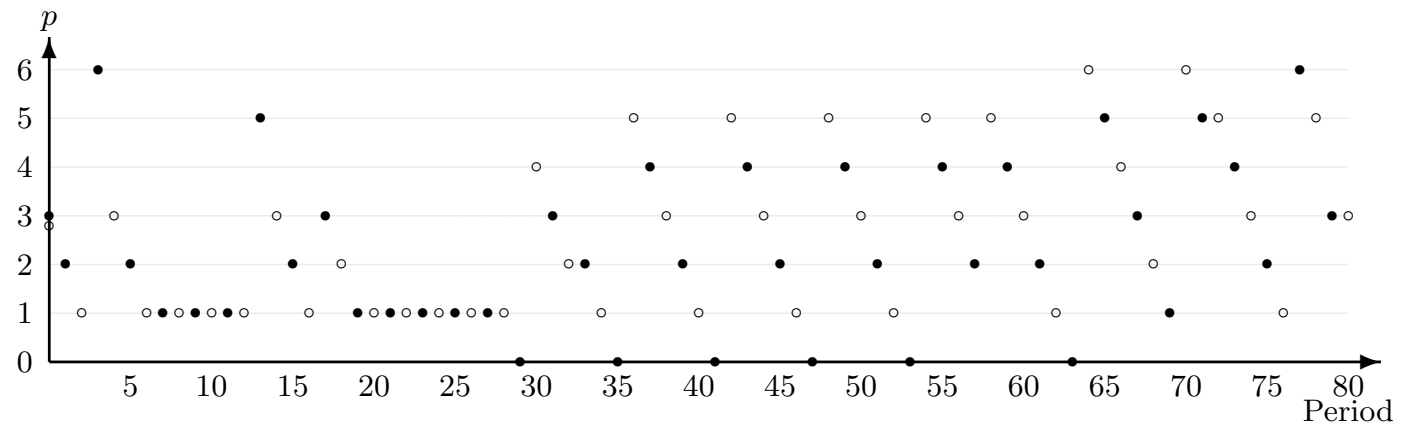

Figure 41: Group F.10

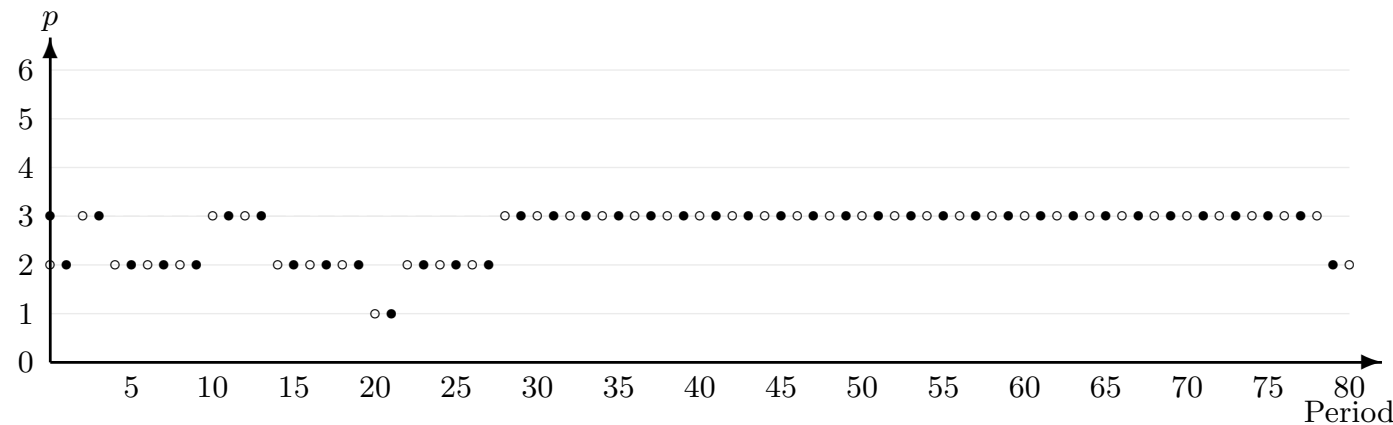

Figure 42: Group F.11 


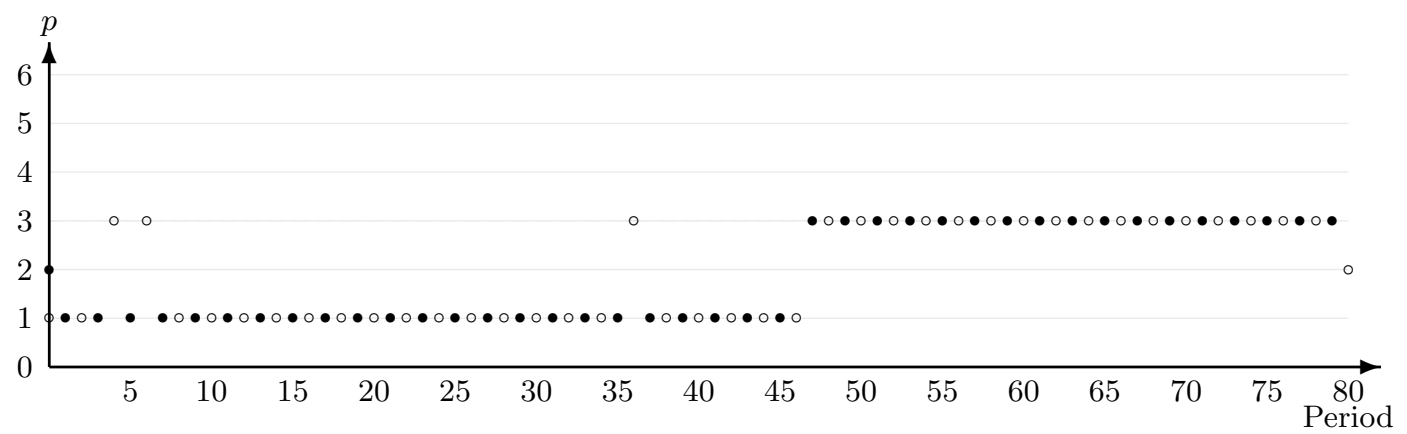

Figure 43: Group F.12

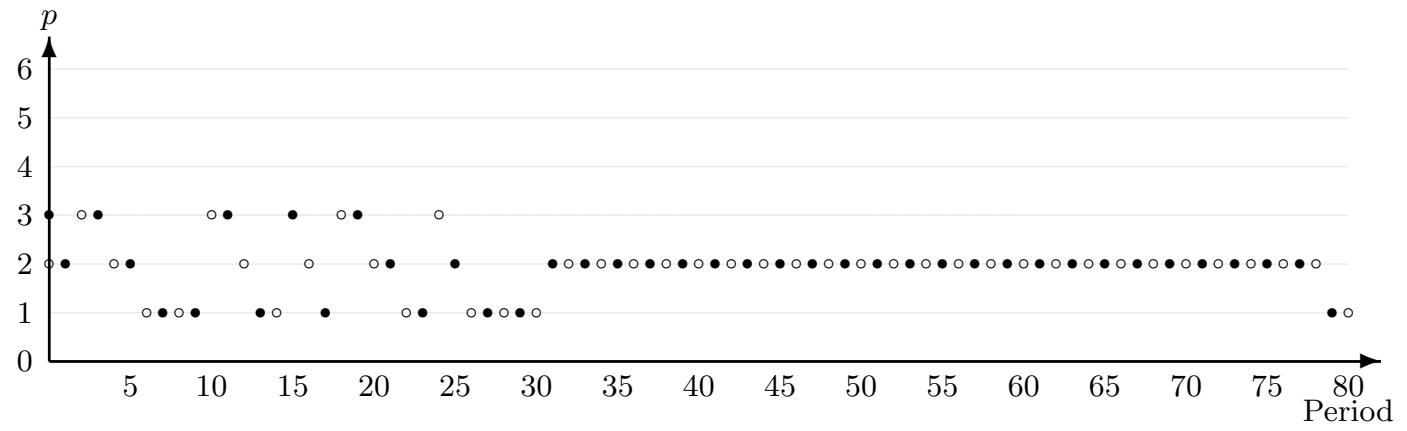

Figure 44: Group F.13

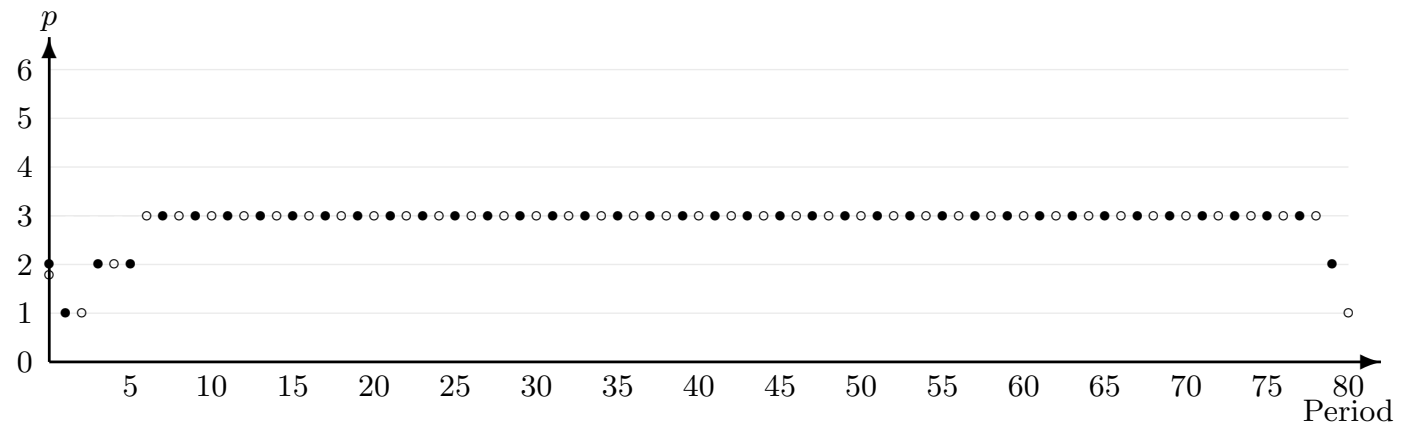

Figure 45: Group F.14

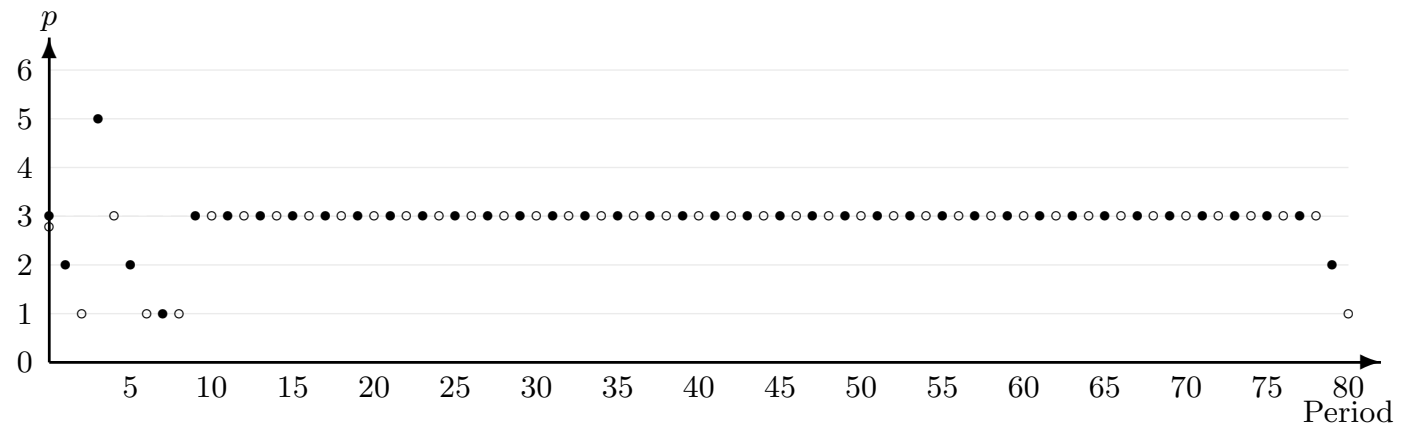

Figure 46: Group F.15 


\section{Instructions}

The instructions that students received before the experiment started are given here. In case the instruction differed for the two treatments, the text for the treatment with random ending is reported between [].

Dear participant, welcome to this experiment. You will be compensated according to your performance. In order to ensure that the experiment takes place in an optimal setting, we want to ask you to follow the general rules during the whole experiment:

- Read these instructions carefully! It is important that you understand the rules of this experiment. These instructions are identical for all subjects that participate together with you. If something is not explained well, please raise your hand. Do not ask the question out loud, but wait until one of the experimenters approaches you to answer the question in private.

- Switch off your mobile phone!

- Do not communicate with your fellow students! Even though the experiment may get exiting at times, it is very important that you remain silent through the proceedings.

- Focus on your own computer screen and not on other participants!

- There is paper and a pen on your table which you can use during the experiment.

- After the experiment, please remain seated until you are paid off.

- If you do not obey the rules, the data becomes useless for us. Therefore we will have to exclude you from this experiment and you will not receive any compensation.

Your decisions and earnings in this experiment will remain anonymous.

\section{General set-up}

In this experiment all of you are sellers of a fictitious commodity. You can earn ECU (Experimental Currency Units) which will be exchanged into Euros at the end of the experiment. The exchange rate will be given in the instructions below.

Before the experiment starts, you will be randomly divided into groups of two sellers. You will not know the identity of the seller you are matched with. The groups remain unchanged throughout the whole experiment. 


\section{Procedures}

This experiment consists of 80 [multiple] periods. In each period, only one of the two sellers can adapt its price. The price of the seller that cannot adapt its price remains equal to its price in the previous period. The seller that can adapt its price switches after each period. Consequently, one seller can adapt its price only in the odd periods, whereas the other seller can adapt its price only in the even periods.

Before setting your price for the current and the subsequent period, you observe the price of the other seller for the current period. Remember that the other seller can adapt its price in the next period, after having observed your price. This procedure of alternating priceadaptation continues until the experiment ends.

Possible prices are the integers between (and including) 0 and 6 . To decide on a price you can select a price on your screen and then click on $O K$ (see the figure below).

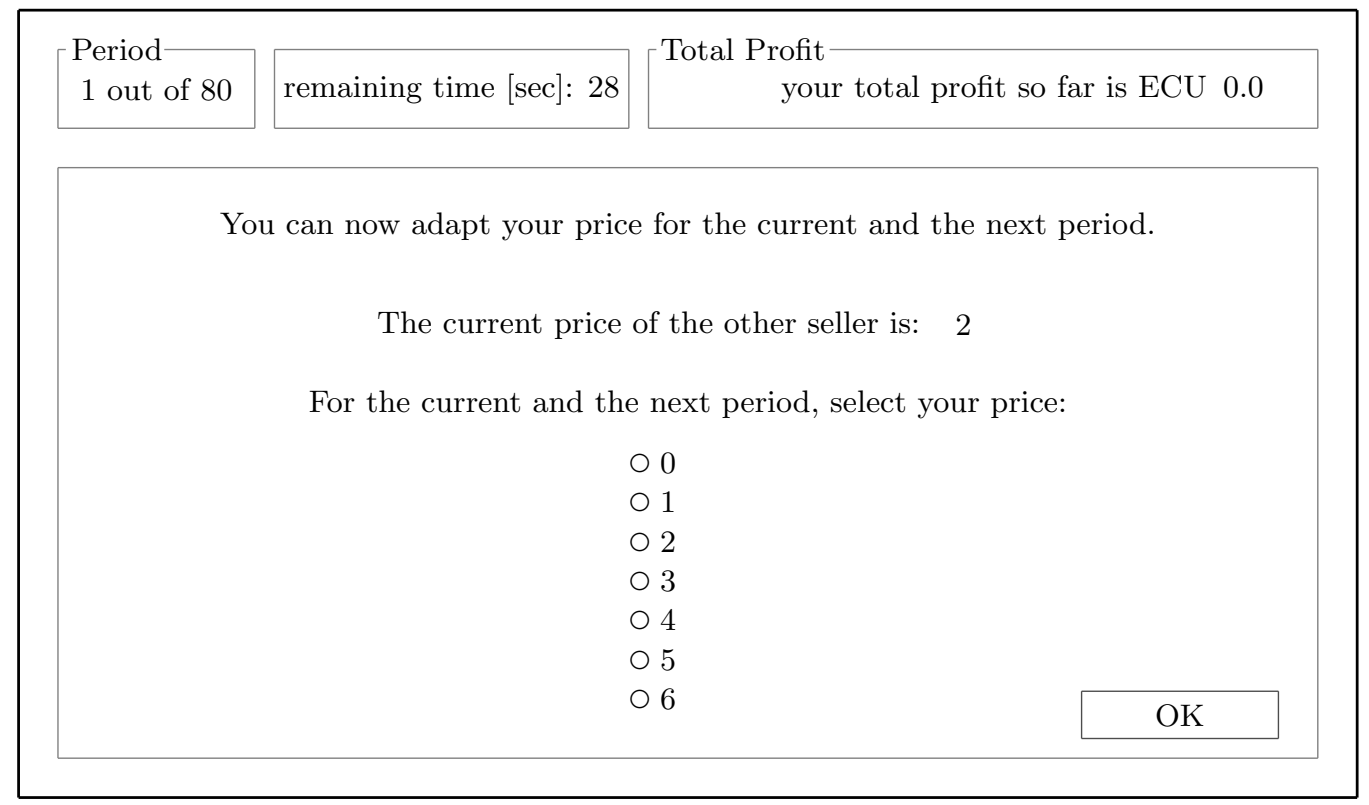

Figure 1: Screenshot of price adaptation screen.

After the seller that could adapt its price has made its decision, the profits for that period are determined. Only the seller that has the lowest price sells output. The amount of output depends on its price. There are no production costs. Hence, the profit for the seller that has the lowest price is equal to the output multiplied by its price. Table 1 shows the output and profit at each possible price for the seller that has the lowest price. The other seller has a profit equal to zero in this period. 


\begin{tabular}{llllllll}
\hline \hline Price & 0 & 1 & 2 & 3 & 4 & 5 & 6 \\
Output & 6 & 5 & 4 & 3 & 2 & 1 & 0 \\
\hline Profit & 0 & 5 & 8 & 9 & 8 & 5 & 0 \\
\hline \hline
\end{tabular}

Table 1: The output and profit for the seller with the lowest price.

In case both sellers have the same price, output is split equally. The profit for each seller is then half of the profit reported in Table 1 at that price.

At the end of each period, both sellers receive an overview of the results of that period. You can observe your price, the price of the other seller, your profit, and your total profit so far. In a period in which you cannot adapt your price, you only observe the result screen of that period.

This procedure continues until the end of the experiment.

\section{[ Number of periods}

The number of periods in this experiment is unknown until the experiment has ended. After each period, the experiment ends with a probability of 2 percent. This means that with a probability of 98 percent the experiment continues with the next period. The decision to continue or not, is made by a computer. Notice that although you are matched with one other seller, the number of periods played will be the same for all subjects in the current session.

\section{The first period}

Before the procedures above start, it has to be decided who of the sellers is able to adapt its price in the first (and all odd) periods and to which price this seller responds. Therefore, the first period contains an initial period in which both sellers are asked to set an initial price. Next the computer randomly decides which of the two sellers can adapt its price in the odd periods. In the first period this seller will respond to the other's initial price.

\section{Closing}

After the last period of the experiment, we would like you to complete a short questionnaire that will appear on your screen. Payments will be made by the experimenters afterwards.

ECU are transformed into Euros according to the following conversion rate: 20 ECU $=1$ Euro. In addition to your earnings during the course of the experiment, you will also receive a show up fee of 5 Euro.

Before we start with the experiment we want you to answer the questionnaire on the next page. One of the experimenters will go around and check the answers and discuss any problems. 


\section{Questionnaire}

Please answer the following questions. When you are finished, raise your hand. One of the experimenters will come to you and check whether everything is correct.

1. How many sellers are in your group (including yourself)?

2. Suppose that you can adapt your price in period 4 . What does this imply for your price in period 5 ?

_ My price in period 5 will be equal to my price in period 4 .

_ My price in period 5 can be any integer between (and including) 0 and 6 .

3. Suppose that you can adapt your price in period 4 . What do you know about the price of the other seller in period 5 ?

_ The other's price in period 5 will be equal to its price in period 4 .

_ The other's price in period 5 can be any integer between (and including) 0 and 6 .

4. Suppose that you can adapt your price in period 4 . What does this imply for your price in period 6 ?

_ My price in period 6 will be equal to my price in period 4 .

_ My price in period 6 will be equal to my price in period 5 .

_ My price in period 6 can be any integer between (and including) 0 and 6 .

5. Suppose you can adapt your price in the current period and the price of the other seller is 5 .

(a) What will be your profit in this period when you set a price of 6 ?

(b) What will be your profit in this period when you set a price of 5 ?

(c) What will be your profit in this period when you set a price of 4 ?

[6. Suppose you are currently in period 17, what is the probability that the experiment continues with period 18 ? 